\title{
An assessment of individual and institutional research utilization by policy-makers and programme managers at state and national levels in Nigeria
}

National Agency for the Control of AIDS

Follow this and additional works at: https://knowledgecommons.popcouncil.org/departments_sbsr-hiv

Part of the Demography, Population, and Ecology Commons, Family, Life Course, and Society Commons, Gender and Sexuality Commons, International Public Health Commons, and the Medicine and Health Commons How does access to this work benefit you? Let us know!

\section{Recommended Citation}

National Agency for the Control of AIDS. 2012. "An assessment of individual and institutional research utilization by policy-makers and programme managers at state and national levels in Nigeria." Abuja: National Agency for the Control of AIDS. 

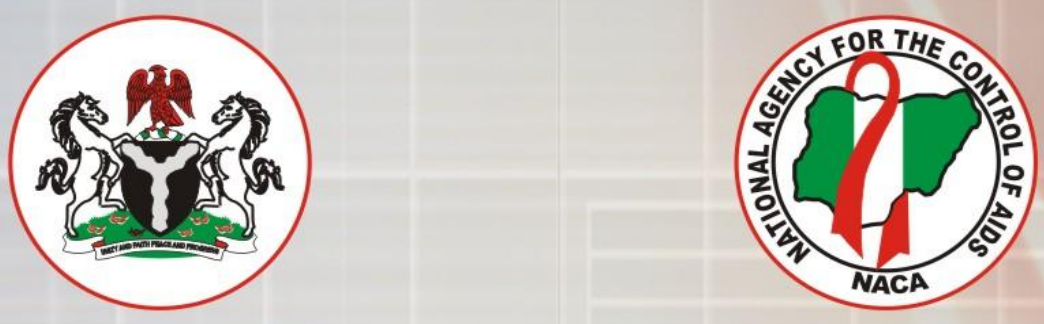

\section{An Assessiment of}

Individual and Institutional Research Utilisation by Policy-Makers and Programme Managers at State and National Levels in Nigeria 


\section{An Assessment of Individual and Institutional Research Utilization by Policy-Makers and Programme Managers at State and National Levels in Nigeria}




\section{Recommended Citation:}

National Agency for the Control of AIDS (NACA): An Assessment of Individual and Institutional Research Utilization by Policy-Makers and Programme Managers at State and National Levels in Nigeria. 2012

ISBN: $978-978-51172-0-2$

\section{TABLE OF CONTENTS}


Acronyms

Glossary of Terms Error! Bookmark not defined.

Acknowledgements viii

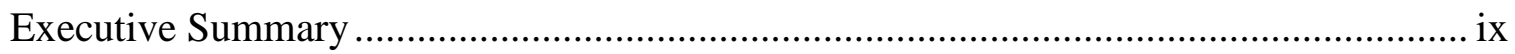

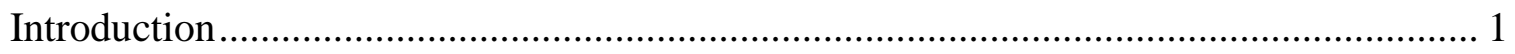

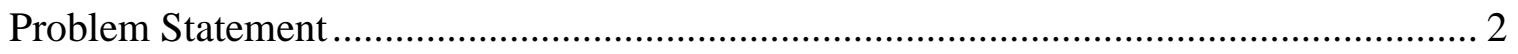

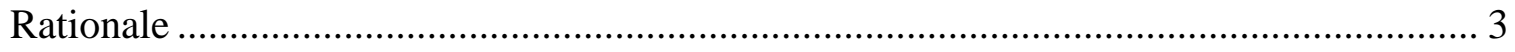

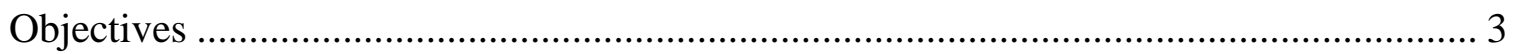

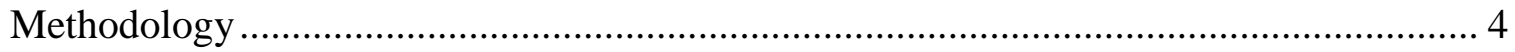

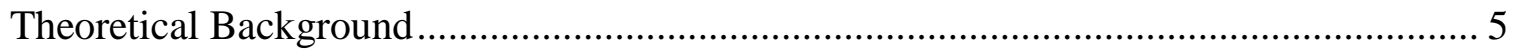

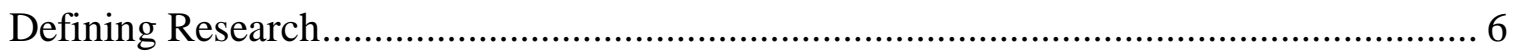

How Can Research Influence Policy-Making and Practice? ........................................ 8

Stages of Research Utilisation and User Interactions ............................................. 8

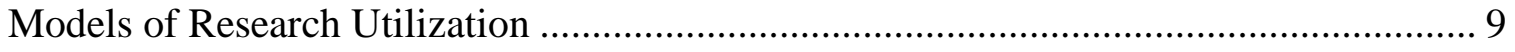

Applying theoretical models to the Nigerian context ................................................. 10

Key Findings: Mapping Nigeria’s Institutional Response to AIDS .............................. 11

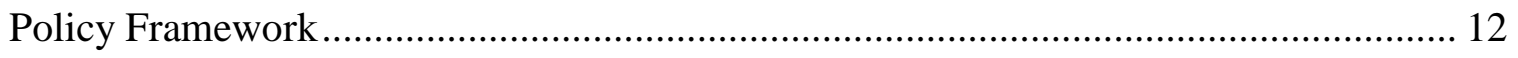

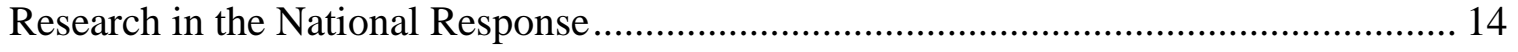

Research Coordination and Management ........................................................... 15

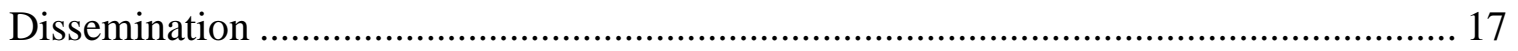

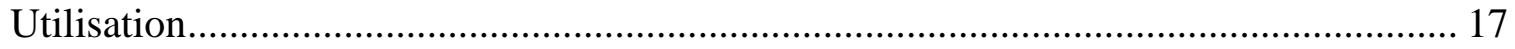

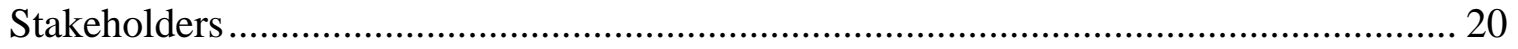

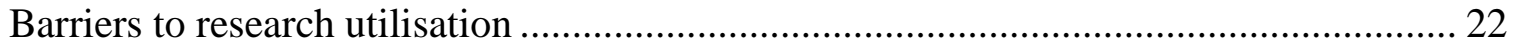

Barriers related to the Gap between researchers, policy-makers and practitioners .......... 22

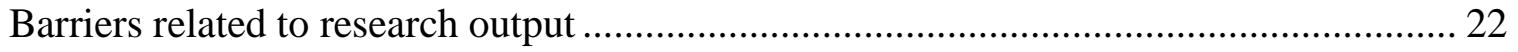

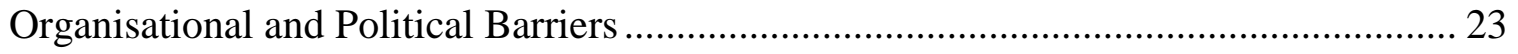

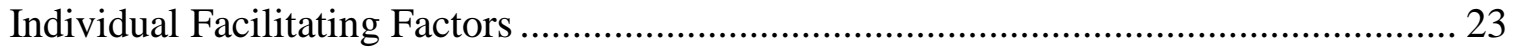

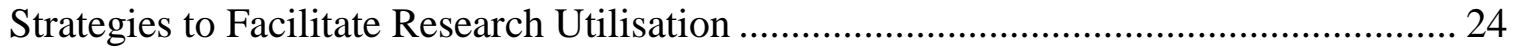

Strengthening interactions between researchers and research users ............................. 24







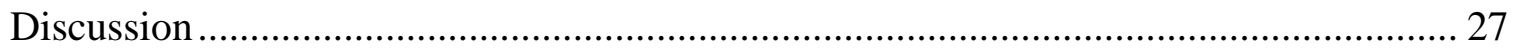

Alternative Models of Research Utilisation - Is there really a gap? ............................. 27 


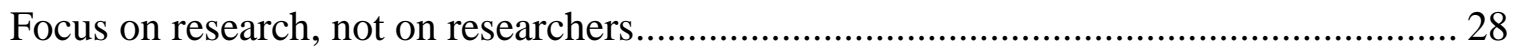



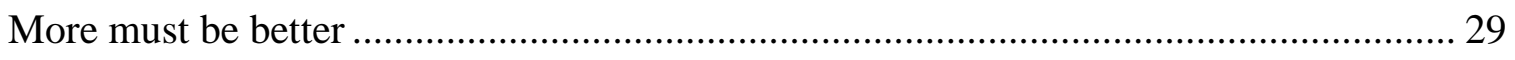

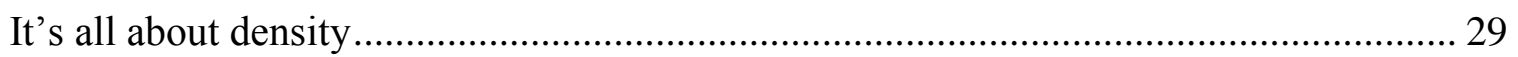

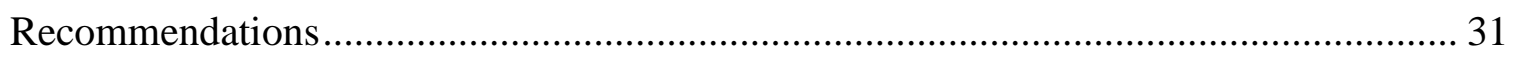

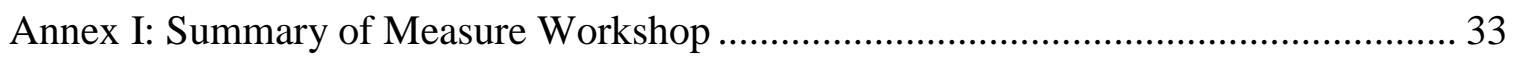

Strengthening the Use of Data to Inform HIV and AIDS Policy and Practice in Nigeria. 33

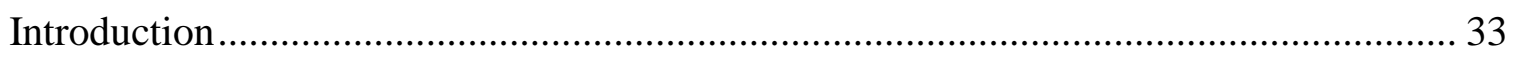

Goal and Objectives of the Assessment Workshop ................................................... 34

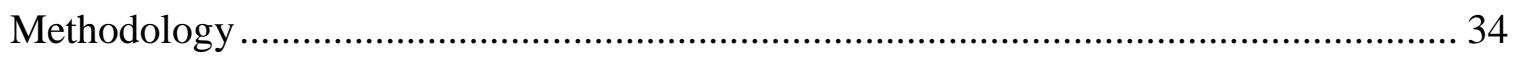

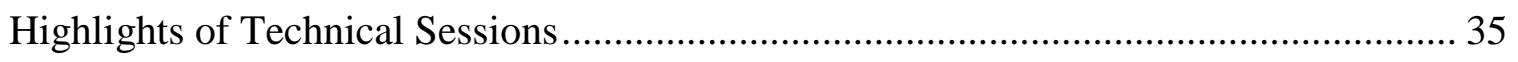

Experience from States on Information Use ........................................................... 35



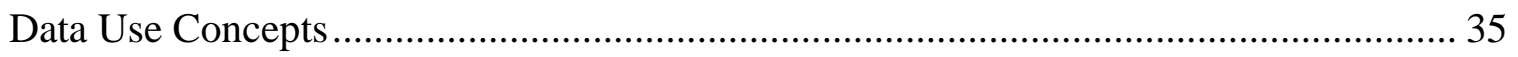

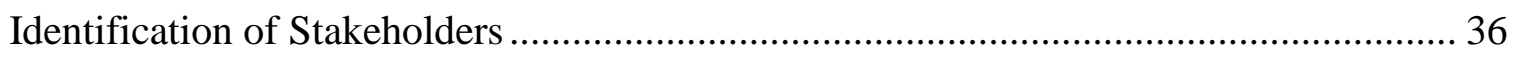

Understanding Information Flow and Information Use Mapping ................................ 36

Barriers to Using Data to Inform Decision-making................................................. 36



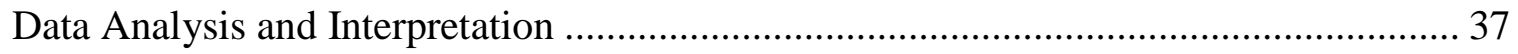

Developing an Action Plan on Linking Decisions with Data ..................................... 37

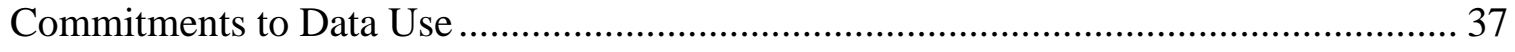

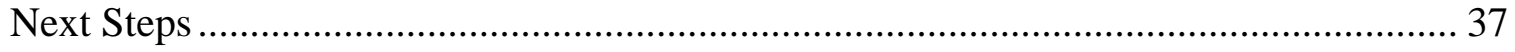

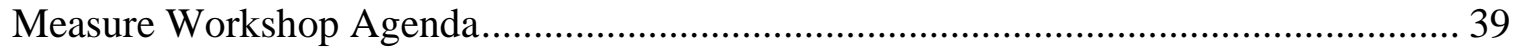

Annex II: Workshop Participants....................................................................... 41

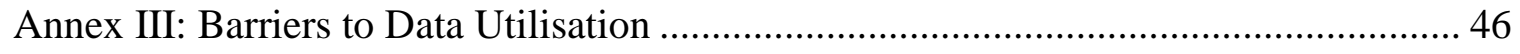

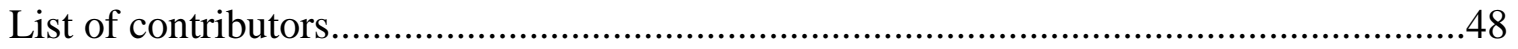

\section{ACRONYMS}

ABC Abstinence, Be faithful, Use Condoms

ANC Antenatal Care 


\begin{tabular}{|c|c|}
\hline ARV & Anti-Retroviral \\
\hline BPA & Budget and Planning Agencies \\
\hline $\mathrm{CBO}$ & Community Based Organisation \\
\hline CISHAN & Civil Society for HIV andAIDS in Nigeria \\
\hline $\mathrm{CSO}$ & Civil Society Organisations \\
\hline DDIU & Data Demand and Information Use \\
\hline DDU & Data Demand and Use \\
\hline DFID & Department for International Development \\
\hline ENR & Enhancing Nigeria's Response to HIV and AIDS Programme \\
\hline FCT & Federal Capital Territory \\
\hline FMOH & Federal Ministry of Health \\
\hline GRIPP & Getting Research Into Policy and Practice \\
\hline HAF & HIV AIDS Fund \\
\hline HCT & HIV Counselling and Testing \\
\hline HIV & Human Immunodeficiency Virus \\
\hline HMIS & Health Management Information System \\
\hline IBBSS & Integrated Bio Behavioural Surveillance Study \\
\hline IDU & Injecting Drug User \\
\hline LACA & Local Action Committee on AIDS \\
\hline LGA & Local Government Area \\
\hline $\mathrm{M} \& \mathrm{E}$ & Monitoring and Evaluation \\
\hline MARP & Most At Risk Population \\
\hline $\mathrm{MCH}$ & Maternal and Child Health \\
\hline MDA & Ministries, Departments and Agencies \\
\hline MSM & Men who have Sex with Men \\
\hline NACA & National Agency for the Control of AIDS \\
\hline NARHS & National HIV/AIDS and Reproductive Health Survey \\
\hline NARH & National AIDS Research Network \\
\hline NASCP & National AIDS STI Control Programme \\
\hline NEPWHAN & Network of People Living with HIVAIDS in Nigeria \\
\hline NGO & Non-Governmental Organisation \\
\hline NHMIS & National Health Management Information System \\
\hline NNRIMS & Nigerian National Response Information Management Systems \\
\hline NIMR & Nigerian Institute for Medical Research \\
\hline NNRELLA & Nigeria Network of Religious Leaders Living with HIVandAIDS \\
\hline NIPR & Nigerian Institute for Pharmaceutical Research \\
\hline NLC & Nigerian Labour Congress \\
\hline NSF & National Strategic Framework \\
\hline NSP & National Strategic Plan \\
\hline OECD & Organisation for Economic Co-operation and Development \\
\hline OVC & Orphans and Vulnerable Children \\
\hline PHDP & Positive Health, Dignity, and Prevention \\
\hline PLHIV & People Living with HIV \\
\hline PLWHA & People Living with HIV and AIDS \\
\hline PMTCT & Prevention of Mother-to-Child Transmission \\
\hline PPP & Public-Private-Partnership \\
\hline
\end{tabular}




$\begin{array}{ll}\text { Q\&A } & \text { Question and Answer } \\ \text { RCT } & \text { Randomised Control Trials } \\ \text { RIU } & \text { Research Into Use } \\ \text { RPC } & \text { Research Programme Consortia } \\ \text { SACA } & \text { State AIDS Control Agency } \\ \text { SFH } & \text { Society for Family Health } \\ \text { SHHEP } & \text { Sexual Health and HIV Evidence into Practice } \\ \text { SMOH } & \text { State Ministry of Health } \\ \text { SRH } & \text { Sexual and Reproductive Health } \\ \text { STI } & \text { Sexually Transmitted Infection } \\ \text { TRIP } & \text { Turning Research Into Practice } \\ \text { TWG } & \text { Technical Working Groups } \\ \text { UCH } & \text { University College Hospital } \\ \text { UNAIDS } & \text { United Nations Program on AIDS } \\ \text { WHO } & \text { World Health Organization }\end{array}$




\section{GLOSSARY OF TERMS}

Data: Factual information, often in the form of numbers obtained from experiments or surveys and used as a basis for making calculations or drawing conclusions.

Evidence: Sign or proof of the existence or non-existence or truth of something, or that helps somebody to come to a particular conclusion.

Knowledge exchange: Collaborative problem-solving between researchers and decision makers.

Knowledge Translation: The exchange, synthesis, and effective communication of reliable and relevant research results. The focus is on promoting interaction between producers and users of research, removing the barriers to research use, and tailoring information to different target audiences so that effective interventions are used more widely.

Policy: A purposive course of action followed by an actor or set of actors.

Research utilisation: The use of knowledge substantiated through research in addressing and solving problems.

Research: Any systematic effort to increase the stock of knowledge. 


\section{ACKNOWLEDGMENTS}

The National Agency for the Control of AIDS (NACA) acknowledges the dedication, efforts and support of all stakeholders that have contributed to the success of this piece of work.

Given the wide gap between evidence generated from research findings, policy and practice, we believe that the application of the GRIPP (Getting Research into Policy and Practice) concept will boost the drive towards closing this gap. This is in tandem with NACA effort to reposition research to play a central role in the national response through various structures and initiatives including establishment of a research division and Programme- Science Approach. Thus, a systematic assessment of the need for evidence by decision-makers working in HIV and AIDS funding or implementing organisations at the national and sub-national levels in Nigeria cannot be over emphasized as evidence drives policy and supports its implementation. Special thanks go to UKAID and the Enhancing Nigeria's Response to HIV and AIDS (ENR) programme and Measure Evaluation for providing financial and technical support to the success of this study. We hope and believe that GRIPP will begin a revolution of research being the backbone of planning, programming and policy making in Nigeria.

Dr Michael Kayode Ogungbemi

Director, Strategic Knowledge Management

NACA, Abuja 


\section{EXECUTIVE SUMMARY}

This report undertakes a systematic assessment of the need for evidence by decision-makers working on HIV and AIDS funding, policy-making, or implementing organisations at the national and sub-national levels in Nigeria. The assessment seeks to identify barriers and constraints to data use, identify best practices, and offer recommendations for the design and prioritisation of strategic approaches to address barriers and constraints in data use and production. Finally, tools to monitor the adoption of evidence in policy and practice are offered.

The need for evidence-based practice in the national response to HIV and AIDS has been widely acknowledged, and incorporated into policy guidance, the National Strategic Plan (2010-2015) and the National Research Agenda on HIV and AIDS (2010-2015). Thus, the political will for more evidence exists, yet this has not translated into the prioritisation and financing of research. Likewise, many stakeholders both on the production and utilisation sides have limited engagement in the design, coordination, dissemination and utilisation of research.

To address these objectives, the National Agency for the Control of AIDS (NACA) in collaboration with Enhancing Nigeria's Response to HIV and AIDS programme (ENR) funded by UKAID DFID and Measure Evaluation supported by USAID, conducted a literature review of knowledge production and utilisation and series of workshops to investigate both policy-maker and practitioner perspectives on data use. This assessment was then complemented with a series of high-level interviews with policy-makers to ensure a cross-section of data producers and consumers was reached.

The assessment identified an increasing number of efforts for getting research into policy and practice. Nevertheless, there is an overall dissatisfaction with the quality, timeliness and relevance of the research. Assumptions were made about the barriers to utilisation, some of which have been borne out to be true as presented in this assessment. Efforts mostly focussed on data production rather than utilisation based on the rationale that one needs data before it can be used. Initiatives to strengthen the institutional capacity of federal and state-level data utilisation have been a priority, however the high cost associated with this effort has hampered activities. This is particularly acute in light of the independence of state and local level response. The exception being the generation of monitoring and evaluation (M\&E) data to guide the planning, 
coordination, and implementation of the national HIV and AIDS response: What is clear, however, is the absence of a strategy for overcoming barriers that impede the utilisation of research has left a noticeable gap in the national response.

The vast majority of data used in the national response is generated through $\mathrm{M} \& \mathrm{E}$ data or periodic surveillance studies coming from NACA or the Federal Ministry of Health's HIV and AIDS Division. Dissemination however is often limited to the National level with no evidence of a strategic or standardised approach to dissemination.

In other areas of research utilisation, the evidence of effective utilisation is less compelling; but at the same time, there is little evidence of a yawning research-to-use gap. Numerous instances where research has influenced policy and practice were identified. More importantly, the perception of the research-to-use gap represents the poor state of research promotion in Nigeria, whereby researchers receive little financial support and suffer a relative lack of connectedness and thus policy relevance. Policy-makers, likewise, rely on their personal and professional networks for relevant policy-informing data, if available when and where needed.

The findings of this assessment support the continuation of current data utilisation promotion efforts as related to skills-building, infrastructure, and targeting of research results. Further, there is a need to address a broader systems approach to knowledge generation. Such a sector-wide approach recognises the interconnectedness between research and utilisation at an institutional level without trying to pick winners, and thus avoids an instrumental 'magic bullet' approach which rarely translates to effective policy change.

An increase in the overall generation of knowledge through improved research quality will contribute to the establishment and maintenance of policy relevance. Knowledge sharing through specialised media publications, individual journalistic investigation, and increased spaces for policy debate will contribute to the overall promotion of knowledge utilisation. Additional efforts which would contribute to greater knowledge utilisation include the cultivation of relevant debates within communities of practice, increased public engagement and scrutiny of the policy-process, and the strengthening the relations between policy-making bodies, political parties, and local think tanks.

While indiscriminate approaches to targeted research should be discouraged, there is a clear need to develop a research utilisation strategy actionable at the sub-sectoral level. Such a strategy 
should target policy-maker perceptions and practice of research use, and provide a demonstrable impact to stimulate greater confidence in the use of data for decision-making.

Finally, to facilitate a systems approach to research utilisation, there is a need to map out the knowledge production and consumption systems in the HIV and AIDS sector at the federal and state levels. A social network analysis will facilitate a better understanding of the political economy of knowledge production and focus communication channels and products on key facilitating institutions and individuals. 


\section{INTRODUCTION}

The first AIDS case in Nigeria was diagnosed in 1986. In the intervening decades, the HIV and AIDS epidemic spread to the current status as generalised based on UNAIDS criteria, with all of the country's 36 states and 774 Local Government Areas (LGAs) affected. The biennial seroprevalence survey conducted among pregnant women attending antenatal clinics at sentinel clinic sites showed infection rates decreased from 5.8\% in 2002 to $4.6 \%$ in 2006 and $4.8 \%$ in 2008 and to the current rate of $4.1 \% .^{12}$

The need for an evidence-driven response to Nigeria's HIV and AIDS epidemic has been widely acknowledged. The National Research Agenda on HIV and AIDS 2010-2015 notes that 'there is a general appreciation among stakeholders of the urgent need for evidence-driven interventions to sustain the best practices in HIV and AIDS response, and to provide fresh insights that will guide programming and policy formulations. ${ }^{3}$ To meet this need, NACA has drafted a policy 'to promote continuous generation and use of nationally-driven, high quality, scientifically-credible, and ethically-sound evidence to improve the understanding of HIV and AIDS epidemic and to guide HIV and AIDS-related policy, practice and interventions'.

The challenges and necessity of evidence-based interventions are considerable and reflected in the National Strategic Plan 2010-2015. The plan identifies the challenges to include lack of national priority research funding and coordination framework, poor dissemination and utilisation of research outputs, poor involvement of stakeholders in research activities, particularly at community level, and low priority accorded by various stakeholders, including international development agencies, in their projects and plans. ${ }^{5}$

\footnotetext{
${ }^{1}$ National Agency for the Control of AIDS: 'National HIVIAIDS Research Policy 2010'. Abuja, n.d.

${ }^{2}$ FMOH ANC HIV Sentinel Survey, Nigeria 2010

${ }^{3}$ National Agency for the Control of AIDS: 'The National Research Agenda on HIV and AIDS 2010-2015', Abuja, July 2010

${ }^{4}$ National Agency for the Control of AIDS: 'National HIVIAIDS Research Policy 2010'. Abuja, n.d.

${ }^{5}$ National Agency for the Control of AIDS, National Strategic Plan 2010-2015. Abuja, January 2010
} 


\section{Problem Statement}

Since the start of the HIV and AIDS epidemic, Nigeria has responded to the epidemic with multiple policy formulation and programming cycles. However, despite the significant investment in bio-medical, behavioural, and policy research, the role of research remains marginal in shaping HIV and AIDS programming, decision-making and practice in Nigeria. Research is largely divorced from implementation. ${ }^{6}$ With the growing expectation for costeffective quality services by governments, health care and research funders, and decisionmakers, it has become imperative for policy-makers and managers to translate research outputs into practical, evidence-informed and impactful decisions and actions.

A number of important initiatives have contributed to the refocusing of the role of research in the policy and practice dialogue in the area of HIV and AIDS prevention, care, support and treatment. Namely, the NNRIMS (Nigerian National Response Information Management System) for routine data collection has ensured that regular, standardised monitoring data for HIV and AIDS are available for policy and program-makers. Continuous rounds of serological and behavioural surveillance have contributed to an extensive body of knowledge on the national HIV and AIDS response, including data on high-risk practices contributing to concurrent vectors of the epidemic at the state and national levels. Most recently, Excel-based program and policy projection tools (HAPSAT ${ }^{7}$ and Modes of Transmission Review) have aided the national response by quantifying vital cost and epidemiological data at the state level to better inform policy and program decisions.

The challenge remains how to convert existing and new knowledge generated by such initiatives into an institutionalised response that meets local needs and requirements. NACA has introduced the Measure Evaluation Data for Decision-making tools to assess the extent to which research is used to shape policy and practice in the HIV and AIDS sector. In 2005, an evaluation of high-

\footnotetext{
${ }^{6}$ Walley J, Khan MA., Shah SK., Witter S., Wei X. (2007) How to Get Research into Practice: First Get Practice into Research. Bulletin of the World Health Organization.

${ }^{7}$ HIV/AIDS Program Sustainability Analysis Tool (HAPSAT)
} 
level decision-makers highlighted the challenges faced in putting research into practice. ${ }^{8}$ Based on the recommendations of the evaluation, extensive efforts were undertaken by NACA to support routine and systematic data collection and use. More recently, two workshops were carried out in which mid-level M\&E staff, program managers, and policy-makers from state and non-governmental organisations analyzed state-level constraints to data use, demand and production. As an outcome of the workshop, critical communication between data consumers and producers was achieved. This initiative covered seven states, two of which are currently receiving the support of ENR. Following the workshops, state level consultations and action plans for data demand and utilization were undertaken as well as a training workshop in operations research attended by key state and national level researchers and policy-makers.

\section{RATiONALE}

This report undertakes a systematic assessment of the need for evidence by decision-makers working in HIV and AIDS funding or implementing organisations. The assessment will support a comprehensive knowledge transfer and exchange strategy that seeks to understand both the content required and the format/methods by which such information should be presented.

\section{OBJECTIVES}

The assessment will:

1. Identify barriers and constraints to data use at state and national levels;

2. Identify best practices in data use;

3. Design and prioritize approaches for addressing the barriers and constraints in data use and production, as well as tools to monitor adoption of evidence in policy and practice.

\footnotetext{
${ }^{8}$ Adewuyi, A. \& A. Akinlo. Measure Evaluation. (2005). Decision Maker Perceptions in Nigeria: An Assessment of Data Use Constraints (Sep).
} 


\section{METHODOLOGY}

This document is the result of consultation and assessment that included a review of literature related to data demand and information use (DDIU), getting research into policy and practice (GRIPP), and knowledge transfer (KT), and knowledge management. The review included policy documents, previous assessments and relevant online resources, as well as extensive stakeholder consultation workshops at national and sub-national levels. Assessment workshops in August 2010 drew in participants from Abuja and the states of Akwa Ibom, Benue, Kaduna, Nasarawa and Ogun.

The workshop facilitation team comprised of HIV and evaluation specialists from NACA, ENR, MEASURE Evaluation and the consulting company charged with preparing the draft strategy. The team was jointly led by Professor Gbenga Sunmola, consultant to NACA's Research Unit, and Dr. Samson Bamidele from MEASURE Evaluation who facilitated the workshop with the assistance of NACA and ENR.

For each 3-day workshop, participants worked with participatory tools developed by MEASURE. These included stakeholder identification, organisational data flow and information use mapping, and templates for barrier identification, data analysis and interpretation and action planning. The objectives of the workshop were to explore how research can shape policy and practice in Nigeria, and to help prepare and roll out a draft data demand and use strategy that outlines the content required, format and methods by which such content should be presented, and the tools for promoting information use.

The specific objectives of the workshop were to:

- Identify barriers and facilitating factors in data demand and information use at national and sub-national levels

- Generate data use action plans for key sectors in HIV and AIDS programming in Nigeria.

- Promote a commitment to data demand and information use at all levels

- Recommend intervention areas to overcome data use constraints. 
The workshop technical sessions followed a methodology that included plenary presentations, group work, and presentation back to plenary. MEASURE Evaluation DDIU tools were used throughout the technical sessions.

Participating state delegations were divided into two workshops, with the first workshop organised around federal and state-level actors, then further divided by agency (SACAs, SMOH and NGOs) rather than functional areas. For the second workshop, participants were divided based on functional groups including: line ministries, departments and agencies (MDAs), budget and planning agencies (BPAs), parastatal research institutions and federal medical centres, civil society organisations (CSOs), SACAs, SMOH and legislators. Grouping by function allowed each group to draw experiences and illustrations relevant to their respective roles and functions, thus engendering richer outputs. A more detailed report of the workshop is at Annex I.

Following the desk review ${ }^{9}$ and workshops, we conducted key informant interviews with stakeholders unable to attend the workshops. These included policy-makers in the executive and legislative branches of government and representatives of the major central coordinating entities, local and international civil society and development partners (see Annex II).

\section{THEORETICAL BACKGROUND}

From the point of view of researchers, practitioners, policy-makers and funders, the question of how to promote and expand the impact of research on policy and practice is paramount. ${ }^{10}$ The UK Department for International Development (DFID) has been at the forefront of efforts to identify and expand the empirical knowledge base to expand research to use. This is particularly so in the area of sexual and reproductive health (SRH) and HIV and AIDS.

In 2001-2002, The Getting Research into Policy and Practice (GRIPP) initiative funded by DfID held a meeting to launch the project 'Maximising the impact of DFID-funded health research'. ${ }^{11}$

\footnotetext{
${ }^{9}$ Documents reviewed included national policy documents, grey literature assessments, and relevant online resources.

${ }^{10}$ Theobald et al. Strengthening the research to policy and practice interface: Exploring strategies used by research organisations working on Sexual and Reproductive Health and HIV/AIDS. Health Research Policy and Systems 2011, 9(Suppl 1):S2

${ }^{11}$ DfID support to knowledge utilisation pre-dates GRIPP, in the early 90's DfID provided seminal support in the agricultural dissemination sector.
} 
The project was a partnership between Population Council, John Snow International (Europe) and two DFID-funded research programmes: Opportunities and Choices and Safe Passages to Adulthood. The project funded a website, developed case studies, and formulated strategies to enhance the use of evidence in decision-making. In collaboration with the World Health Organization's (WHO) Department of Reproductive Health and Research and the Turning Research into Practice (TRIP) Task Force, a TRIP toolkit was developed to increase and improve research utilisation. ${ }^{12}$ Parallel efforts to improve communications for research and to measure research impact have been sponsored by DfID. ${ }^{13}$ In 2005, DfID's "Golden Rule" set the bar for research communication, recommending a "minimum of $10 \%$ of the overall Research Programme Consortia (RPC) budget should be spent on communication of research."14

More recently, DfID-sponsored efforts have focused on research-policy interface and the challenge in understanding the multiple contexts and variables that affect the relationships between the two sectors. The Sexual Health and HIV Evidence into Practice (SHHEP) initiative, a collaboration of four DfID supported organizations, has consolidated learning on research utilisation through global and country-specific case studies in the SRH sector. ${ }^{15}$

\section{Defining Research}

In this review, we use a general definition of research as "any systematic effort to increase the stock of knowledge". ${ }^{16}$ This may include any systematic process of critical investigation and evaluation, theory building, data collection, analysis and codification related to development policy and practice. It also includes action research and reflections by practitioners oriented toward the enhancement of direct practice. In terms of the nature of evidence and policy influence, key issues are:

\footnotetext{
${ }^{12}$ Nath, S. Final Report: Getting Research into Policy and Practice (GRIPP). JSI Europe. July 2007

${ }^{13}$ The DFID Research Communications Review (conducted in 2003 (http://www.dfid.gov.uk/research/Comms Strategy Final.pdf)

${ }^{14}$ DfID. Communications Team. Communication of Research: Guidance Notes for Research Programme Consortia Version 1: October 2005. Central Research Department, The Communication and Information Management Resource Centre (CIMRC). Pp. 4.

${ }^{15}$ Theobald et al. Strengthening the research to policy and practice interface: Exploring strategies used by research organisations working on Sexual and Reproductive Health and HIV/AIDS. Health Research Policy and Systems 2011, 9(Suppl 1):S2

${ }^{16}$ The definition is from the OECD (1981). These key elements of evidence are based on RAPID work and a paper by Louise Shaxson.
} 
- Quantity and quality of the evidence;

- Relevance of evidence for policy; e.g. is it timely, topical, and operational; and,

- Credibility of evidence - including considerations of objectivity of sources; extent of contestation; generalisability.

Policy is a "purposive course of action followed by an actor or set of actors". ${ }^{17}$ This goes beyond documents or legislation to include activities on the ground. Policies are not restricted to government policies but could include those of international organisations, bilateral agencies or NGOs. Policy processes are usually considered to include the following components:

- Agenda Setting: awareness of and priority given to an issue or problem;

- Policy Formulation: the ways (analytical and political) options and strategies are constructed;

- Decision-making: the ways in which decisions are made about alternatives;

- Policy Implementation: the forms and nature of policy administration and activities on the ground;

- Policy Evaluation: the nature of monitoring and evaluation of policy need, design, implementation and impact.

In practice, the term 'research' is used differently by various actors, such as academic and nonacademic researchers, policy-makers, and programme managers. A number of studies report that perceptions vary as to what constitutes research.

Health research can be categorised into three domains: basic, clinical and applied research (Hanney et al., 2003). ${ }^{18}$ Basic research refers to traditional academic research with an internal agenda and little focus on non-academic utilisation. In contrast, clinical and applied research follows an agenda influenced by non-academic factors and professionals and is thus more likely to be used by non-academics.

\footnotetext{
${ }^{17}$ The definition is from Anderson (1975). The components of the policy process are from: Hill (1997), Lindblom (1980), Sabatier (1999).

${ }^{18}$ Hanney, S.R., Gonzalez-Block, M.A., Buxton, M.J. \& Kogan, M. 'The utilisation of health research in policy-making: concepts, examples and methods of assessment'. Health Research and Policy Systems, 1(2), January 2003.
} 
A 'hierarchy of evidence' exists in which some types of research are perceived to be more valid than others. ${ }^{19}$ DfID supports the use of multiple methods for impact evaluation, but this trend most recently favours randomised control trials (RCT) and counter-factual experiments. At the same time, DfID recognises the need to find standard indicators which capture non-material impacts and are sensitive to social difference. This work also stresses the importance of supplementing standard indicators with narrative that can identify those dimensions of poverty that are harder to measure.

\section{How Can Research Influence Policy-Making and Practice?}

Research can influence policy either through instrumental or conceptual approaches. Instrumental change refers to the impact on specific policy, practices or behaviour (see Davies et al. 2005; Mandell et al. 2001). At a more aggregate level, conceptual impact refers to influence that causes a change in people's knowledge, understanding and general intellectual orientation towards a subject. Research impact may be applied simultaneously as instrumental and conceptual, such as the introduction of clinical guidelines on STI treatment. Alternatively, research may be applied sequentially as instrumental and then conceptual. Impact can be measured by the degree and extent of utilisation, either as substantive (addresses the core of a policy, practice or intellectual orientation) or elaborative (a narrow aspect of a policy, practice or orientation) (Mandell et al. 2001)

\section{Stages of Research Utilisation and User Interactions}

Knott and Wildavsky's six stages of knowledge utilisation characterise a linear process of research utilisation: transmission of research; cognition of findings; reference to significant studies; efforts to operationalise findings; influence seen on decisions; and application of research to policy and/or practice ${ }^{20}$ Critics cite the inadequacy of linear models in describing the reality of research use, which is often haphazard and incremental. Rarely does research exert an impact directly in a clearly identifiable and instrumental manner, leading to direct policy choices or organisational processes. Rather, research may provide 'a background of empirical

\footnotetext{
${ }^{19}$ Evans, D. (2003) Hierarchy of evidence: a framework for ranking evidence evaluating healthcare interventions. Journal of Clinical Nursing 2003; 12: 77-84

${ }^{20}$ Knott J, Wildavsky A (1980). If dissemination is the solution, what is the problem? Knowledge: Creation, Diffusion, Utilization, 1(4):537-78.
} 
generalisations and ideas that creep into policy deliberation'. ${ }^{21}$ Under such conditions, the pathway by which research influences decisions may be indefinable, appearing only as tacit knowledge, values, discourse, and debate in the public sphere. Lavis et al. (2003) ${ }^{22}$ characterises three basic types of research/user interaction: producer-push, user-pull, and exchange. Producerpush refers to the role of researchers in communicating the findings from their research. Userpull identifies the need for users to create a conducive environment where research is valued, sought and used. Last, exchange hypothesizes that open, equitable interaction between researchers and users will foster collaboration in the creation, validation and use of research.

\section{Models of Research Utilization}

Research utilization may be divided into two broad categories: individual and organisational. Individual models focus on instrumental, problem-solving interactions between researchers and institutions. ${ }^{23}$ Variations of these models are labelled knowledge-driven, problem-solving, policydriven, and interactive. A less instrumental, but close variation is the enlightenment model in which research utilisation and impact results from 'the gradual sedimentation of insight, theories, concepts and perspectives'. ${ }^{24}$ Individual models may focus less on knowledge and more on the political sphere. In this case, knowledge is harnessed for political and not policy aims, either to support decision-making or to deflect pressure for action. ${ }^{25}$ Individual models are characterized by non-linear, less predictable knowledge and policy outcomes, depending on personal interactions between researchers and users through one-off or sustained interactions.

\footnotetext{
${ }^{21}$ Weiss CB (1980). Knowledge creep and decision accretion. Knowledge: Creation, Diffusion, Utilization.1(3):381-404.

${ }^{22}$ Lavis, J., Robertson, D., Woodside, J.M., McLeod, C.B., \& Abelson, J. (2003). 'How can research organizations more effectively transfer research knowledge to decision makers?' The Millbank Quarterly, 81(2).

${ }^{23}$ Assessing the impact of social science research: conceptual, methodological and practical issues $\mathrm{A}$ background discussion paper for ESRC Symposium on Assessing Non-Academic Impact of Research May 2005 Prepared by: Huw Davies, Sandra Nutley, Isabel Walter Research Unit for Research Utilisation School of Management, University of St Andrews.

${ }^{24}$ Assessing the impact of social science research: conceptual, methodological and practical issues A background discussion paper for ESRC Symposium on Assessing Non-Academic Impact of Research May 2005 Prepared by: Huw Davies, Sandra Nutley, Isabel Walter Research Unit for Research Utilisation School of Management, University of St Andrews.

${ }^{25}$ Estabrooks, C. A. (1999). The conceptual structure of research utilization. Research in Nursing \& Health, 22, 203-216.
} 
Organisational models of knowledge utilisation place the actor within an institutional context. The evidence-based practitioner model highlights the role of individual practitioners who create demand for research and then apply the research base to meet their individual and organisational needs. The embedded model relies upon the incorporation of research evidence into organisational procedures, protocols and guidelines. Learning is a management responsibility where research is identified and instilled into institutional routines. Finally, the organisational excellence model requires localised strategies of continuous improvement and experimentation based on an organisational ethos of reflexivity, inquisitiveness, and willingness to change. ${ }^{26}$ Organisational typologies provide a framework to categorise research use environments and to understand the research-to-use gap according to the dominant modes of research uptake and use. The framework further highlights the importance of organisational initiatives as a precursor to interventions to address the research-to-use gap. ${ }^{27}$

\section{Applying theoretical models to the Nigerian context}

In reviewing the theoretical underpinnings of the research-to-practice space in Nigeria, a number of clear distinctions emerge. Evidence in the Nigerian context is characterised in hierarchical fashion, with research producers and consumers occupying separate spaces. This contrasts with the haphazard and often contradictory processes in which research is translated into practice. For instance Nigeria, like other contexts, has a high degree of movement and fluidity between the research utilisation and production fields. Research utilisation is likewise framed around the structured summarisation of research findings to mixed audiences who are then left to interpret. These interactions are invariably dominated by 'information telling' approaches rather than 'knowledge construction' approaches. ${ }^{28}$

\footnotetext{
${ }^{26}$ Walter I, Nutley SM, Percy-Smith J, McNeish D, Frost S (2004). Improving the use of research in social care. Knowledge Review 7, Social Care Institute for Excellence/ Policy Press: London.

${ }_{27}$ Walter I, Nutley SM, Percy-Smith J, McNeish D, Frost S (2004). Improving the use of research in social care. Knowledge Review 7, Social Care Institute for Excellence/ Policy Press: London.

${ }^{28}$ Levin, M. and Greenwood, D. (2001), 'Pragmatic action research and the struggle to transform universities into learning communities', in P. Reason and H. Bradbury (eds.) Action Research Participative Inquiry and Practice, Sage, London pp103-113
} 


\section{KEY FindingS: MAPPING NigERIA’s InSTITUTIONAL RESPONSE TO AIDS}

While there have been few formal activities for getting research into policy and practice, this has not prevented research from being utilised. Nevertheless, the absence of a strategy for overcoming the barriers that impede an optimal contribution from research has left a noticeable gap in the national response.

Science in Africa as a whole is dominated by four countries: South Africa, Egypt, Nigeria and Kenya. Between 1999 and 2008, South Africa produced nearly 47,000 papers across disciplines, almost 30,000 for Egypt, 10,000 for Nigeria and 6,500 for Kenya. Nigeria ranks second in the production of social science journal articles and fourth in bio-medical science articles based on Thomson Reuters Essential Science Indicators database during the five-year period 2004-2008. Nigeria has an important connecting role among Anglophone collaborative networks in West Africa as well as a strong connection with South Africa. ${ }^{29}$

The gap between research and practice is not limited to the health sector in Nigeria. A country assessment conducted in Nigeria by the Research into Use (RIU) programme found that knowledge outputs from the nation's 18 agricultural research institutes were not being utilised by intended users owing to institutional and other barriers. ${ }^{30}$

The principal policies underpinning research utilisation include the NACA Act, the National Policy on HIV and AIDS 2010-2015, National Strategic Plan 2010-2015, the National Research Agenda and the National Research Policy. The NACA Act recognizes the agency as the central coordinating authority for HIV and AIDS activities in the country and therefore ultimately the steward of research to utilisation. The National Policy on HIV and AIDS recognizes research and knowledge management as one of the seven thematic areas for policy action. The National Strategic Plan has identified the challenges inhibiting the generation and utilisation of research knowledge and has proposed interventions to address these.

In September of 2005, Measure Evaluation conducted an assessment of decision-maker needs and barriers to data use. The report highlights the lack of clarity among decision-makers as to how policy is formulated at the national level. Rationalisation of organisational structures,

\footnotetext{
${ }^{29}$ Adams, J. et al. Global Research Report: Africa. April 2010

${ }^{30}$ Research into Use Project, Nigeria, 2007.
} 
processes and flow of data for decision-making was clearly needed, with lower levels in the administrative hierarchy (local and state agencies) almost entirely dependent on officers at the national level for analysis and interpretation of the information that they collect. Capacity of lower-level staff to manage and interpret data lagged significantly. Efforts to train staff failed for the most part because of the ad hoc nature of the efforts and concomitant costs of equitably distributing workshops across the country's geo-political zones. Once trained, staff lacked a supportive environment to sustain their new skills. ${ }^{31}$

At the national level, effective policy-making is further hampered by a lack of valid and reliable data. Other constraints were seen to inhibit evidence-based policy formulation including political interference, under-funding, and poor management. The study recommended organisational-level interventions to develop data-generation capacity in key institutions, promote the value of data use, and create a National Health Management Information System (NHMIS) as a "credible and readily accessible databank as a way of avoiding duplication of data generation by various agencies, thereby reducing cost and time spent on acquiring data for policy formulation." 32

Based on lessons learned from past efforts, we sought to delineate approaches and priorities for addressing many of the downstream aspects of research utilisation, also contribute to the upstream policy dimensions. While the priorities and objectives we set forth are derived from these policy documents, we base our observations and recommendations on interviews with key stakeholders representing government and civil society, at national, sub-national and international levels.

\section{Policy Framework}

Nigeria's initial strategic response was formulated within the framework of a HIV and AIDS Emergency Plan 2001-2004, which focused on mobilizing multi-sectoral and cross-tier commitment and action by key stakeholders at the national and sub-national levels. The National Strategic Framework (NSF) 2005-2009 focused on critical strategies aimed at preventing new HIV infections and promoting behaviour change. These strategies included greater emphasis on

\footnotetext{
${ }^{31}$ Adewuyi, A. and A. Akinlo. (2005) Decision Maker Perceptions in Kenya and Nigeria: An Assessment of Data Use Constraints. MEASURE Evaluation www.cpc.unc.edu/measure. TR-07-44. Sep.

${ }^{32}$ Adewuyi, A. and A. Akinlo. (2005) Decision Maker Perceptions in Kenya and Nigeria: An Assessment of Data Use Constraints. MEASURE Evaluation www.cpc.unc.edu/measure. TR-07-44. Sep.
} 
HCT, PMTCT, prevention of biomedical transmission, early detection and treatment, the control of STIs, integration of sexual and reproductive health services, and a public communication campaign alongside more targeted interventions among the most-at-risk populations.

The current National Strategic Plan 2010-2015 aims 'to reposition HIV and AIDS prevention as the centrepiece of the national HIV and AIDS response' by 'scaling-up HIV and AIDS prevention services that enable individuals to maintain their HIV negative status as well as improve access to quality treatment and care services for PLHIV including positive health, dignity and prevention (PHDP) interventions that reduce their transmitting HIV to others'. ${ }^{3}$ Unlike the 2005-2009 NSF, the 2010-2015 NSP identifies key considerations relevant to research utilisation, including understanding the burden of the disease; building capacity to respond; equity by gender, age, geography, and class; targeting of MARPs; understanding the modes of transmission and drivers of the epidemic; and understanding stigma and discrimination, along with culture, traditions and religion.

Nigeria's national response mirrors the dynamism of the country's federal structure. The National Agency for the Control of AIDS (NACA) is the central coordinating authority and the linchpin of the multi-tier and multi-sector array of public agencies. NACA's coordination of the national response requires building relationships with state and non-state actors across several tiers of government and civil society. ${ }^{34}$ NACA categorizes actors into five groups: SACAs, CSOs, and private sector, public sector, and development partners. The Agency also works closely with the Federal Ministry of Health's HIV and AIDS Division (formerly National AIDS STI Control Programme (NASCP)) and federal line ministries.

NACA sponsors platforms for interacting with SACAs and provides technical, financial and managerial oversight for World Bank HAF projects in several states. NACA convenes Technical Working Groups (TWGs) that coordinate joint planning and provide technical backstopping. The agency has also helped to form, fund and build the capacity of CSOs and their networks as coordinating entities, creating platforms for program activities. A Public-Private Partnership (PPP) forum has been created to leverage private sector resources, although the engagement has so far been largely limited to multinationals. NACA has also forged partnerships with

\footnotetext{
${ }^{33}$ NSP, p26

${ }^{34}$ NSP $2010-2015$
} 
development partners to leverage donor resources for the national response. A NACA-Donor interaction platform and a Donor Coordination Group have been created along with a Joint Funding Agreement to streamline and track funding and strengthen resource application.

States, via SACAs and relevant units within respective state ministries of health, have considerable autonomy in setting targets and appropriating their resources to achieve them. Federal authorities can facilitate these by setting standards and protocols and by helping with resource mobilisation, but the states must decide how much effort and resources they commit to the fight against HIVandAIDS. Local Government Areas (LGAs) are autonomous entities but rely greatly on state-level inputs and commitments. The collaborative actions of the states and the LGAs have led to significant contributions in addressing the HIV epidemic, specifically in terms of mobilising civil society organisations and businesses through the World Bank's HIV and AIDS Fund (HAF). ${ }^{35}$ The SACAs have similar leadership and coordinating roles, including strategic oversight of the LGA Action Committees on AIDS (LACAs). As with NACA, the governing boards of the SACAs include stakeholders reflecting the diversity of the actors in the national response.

The response at sub-national level is largely dependent on development partner resources. Political commitment at the state level is weak: few state governments are willing or able to fund HIV and AIDS activities beyond the counterpart contribution to the World Bank MAP credit. The State-level HIV response suffers from poor political commitment. For the most part interventions have not been evidence-led: policies, funding, human resource allocation and programs were not always based on local epidemiology.

\section{Research in the National Response}

Since the first national strategic plan (2005) research has figured prominently in the national response to HIV and AIDS. Recent initiatives to translate this increasing awareness into action include the drafting of the national research policy aimed at promoting research and utilisation of research results, building capacity in research ethics and establishing two ethics committees, and initiating training activities. To further strengthen the platform for evidence-based policy and

\footnotetext{
${ }^{35}$ National Strategic Plan, p51.
} 
programming, the National AIDS Research Network (NARN) compiled abstracts of presentations by Nigerians at local and international meetings.

Strategic generation of data in Nigeria has been limited primarily to monitoring and evaluation (M\&E) data to guide the planning, coordination, and implementation of the national HIV response. ${ }^{36}$ M\&E serves as a broader umbrella under the NSF and NSP as a platform for research and knowledge management across thematic areas. The NSP acknowledges shortcomings in the sector, including the 'lack of national priority research funding and coordination framework, poor dissemination and utilisation of research outputs, poor involvement of stakeholders in research activities, particularly at community level, and low priority accorded by various stakeholders, including international development agencies, in their projects and plans. ${ }^{37}$ The NSP cites challenges due to gaps in human resource capacity, poor quality data, inadequate utilisation, low participation of private sector actors and the proliferation of M\&E sub-systems. The document sets forth targets by 2015 to address these shortcomings, including improved coordination and cost-effectiveness of data collection, analysis, and use of program data to inform program planning and decision-making by HIV and AIDS stakeholders at all levels of response. $^{38}$

\section{Research Coordination and Management}

Researcher participation, a vital contributor to the national response, has received marginal recognition and role in terms of influencing decision-making, funding, and learning. Perhaps the best illustration of this marginal role of research is the limited influence of NARN, which was formed to serve as a platform for researchers in the HIV and AIDS sector to share knowledge and emerging practice. The network is responsible for carrying out research by its members and building capacity of civil society organisations to conduct independent research. NARN's achievements include operations research mainly among institutions such as the University College Hospital (UCH), Nigerian Institute for Medical Research (NIMR) and the National Institute for Pharmaceutical Research (NIPRID). NARN's role to date has been eclipsed by

\footnotetext{
${ }^{36} \mathrm{NSP}, \mathrm{Ibid}, \mathrm{p} 60$.

${ }^{37}$ NSP, Ibid. p25

${ }^{38}$ NSP, Ibid.
} 
better-resourced entities such as CiSHAN or NEPHWAN, sister organisations founded at the same time.

An estimated $70 \%$ of data used in the national response is generated by Federal Ministry of Health's HIV/AIDS Division (formerly National AIDS and Sexually Transmitted Diseases Control Program (NASCP)), including the ante-natal care (ANC) HIV sentinel survey, National HIVandAIDS and Reproductive Health Survey (NARHS), Integrated Bio-Behavioural Surveillance Study (IBBSS) and routine Prevention of Mother to Child (PMTCT) data. ${ }^{39}$ NASCP gathers the data in two main ways: a) directly from the Health Management Information System (HMIS) where data transmission flows from peripheral sites (notably health facilities) through the Local Government Authority (LGA) and state HMIS to the national HMIS, and b) surveys such as the ANC sentinel studies, NARHS and IBBSS.

Additionally, NACA (and to a lesser extent SACAs), typically in collaboration with development partners, commission studies that range from desk research to major surveys. Recent examples include the National AIDS Spending Assessments and the Sustainability Analysis of HIV and AIDS Services and various epidemiological surveys (e.g. the Modes of Transmission study), spending analyses and policy syntheses.

National and state-level NGOs and CSOs, including the umbrella body CISHAN, all take part in some form of research activities. CISHAN has assessed the key delivery and thematic areas of all CBOs in the country to identify the strengths and gaps of the civil society response, although the findings have not been disseminated. ${ }^{40}$ CISHAN also conducted an assessment of the impact of CSOs on service delivery areas, a mid-term review of the out-of-school youth prevention program, a study on the provision of support to OVCs, and the provision of home care to PLWHAs outside health facilities. NINRELA collects data on stigma reduction, mostly drawn from the experience of PLWHA in the areas where NINRELA works. SFH, the leading social marketing and behaviour change NGO in Nigeria, has conducted or commissioned studies on various aspects of sexual and reproductive health behaviour. Action Aid has similarly conducted studies including the DFID-sponsored 2003 assessment of CSOs engaged in HIV/AIDS activities, as well as a capacity assessment of NACA, SACAs and LACAs.

\footnotetext{
${ }^{39}$ Interview with Dr Azeez Aderemi, Head of Strategic Information, NASCP.

${ }^{40}$ Interview with Bukola Ehimate, M\&E Manager, CISHAN
} 
International development partners tend to conduct their own research and generate data for their own programming needs and for policy advocacy. They do so both in collaboration with Nigerian partners and independently. Examples of development partner research include the recent World Bank-sponsored assessment of the impact of civil society interventions in reducing the burden of HIV and AIDS, conducted in collaboration with NACA; UNDP's capacity assessment of CSOs and NACA; and a capacity assessment of nine states. Population Council under the auspices of ENR carried out a number of operations research activities in the past two years, including an assessment of HIV/STIs among IDU and MSM, and the use of audiocomputer-assisted self-interviewing (ACASI) among IDU and MSM.

\section{Dissemination}

During the stakeholder interviews, no evidence of a strategic or standardised approach to dissemination was identified. Each producer of research data may use a variety of approaches to disseminate results. NASCP carries out dissemination activities using media outlets and publications circulated to policy-makers, program managers, and the public, with little or no customisation to the needs of the audience. NASCP does not systematically monitor the use of the results and cannot determine whether their research contributes to policy or practise. NACA and some SACAs similarly strive to share findings with stakeholders in the national response through dissemination events and traditional media outlets, publications, and online documentation on the NACA website. CSOs tend to disseminate in more narrow communities, and customise their data to enhance their fundraising appeals. CSOs disseminate more strategically through advocacy and development and placement of communications materials.

\section{Utilisation}

While the common perception of utilisation remains low, many examples of utilisation in Nigeria can be found. ANC sentinel survey data contributed to a wider distribution of HCT services to states with higher sero-prevalence rates, such as Benue, Cross River and the FCT. ${ }^{41}$ NASCPgenerated data are also used for forecasting the numbers of persons requiring ARV and thereby to make projections regarding ARV needs. It is also utilised to monitor the effect of

\footnotetext{
${ }^{41}$ Interview with Dr Azeez Aderemi, Head of Strategy, NASCP.
} 
interventions. For example, data generated on condom use at last high risk sex with a noncohabiting partner are used to analyse the effectiveness of prevention messages and their effect on behaviour change.

CSOs employ their own research for programmatic functions such as advocacy and programme improvement, as well as for proposal writing and reporting to donors. CISHAN has been at the forefront in the HIV and AIDS and SRH sectors through assessment of key delivery and thematic areas of CBOs in country, with the objective of identifying strengths and gaps in the civil society response. Non-academic research plays an important role in providing information for policy-making and practice. Additional examples of research utilisation identified through our assessment, include:

- Setting new objectives, targets and standards: Perceptions/feedback collected from beneficiaries of NINRELA's work informed the adoption of a new model - Safe Practices, Access to Treatment, Voluntary Counseling and Testing and Empowerment (SAVE) — as a substitute for the ABC model advocated by NACA, while the experiences of PLWHA informed the advocacy that led to the initiation of the anti-stigma bill currently in the National Assembly. ${ }^{42}$

- Finding solutions to specific issues at national and sub-national levels: Research has promoted ARV policy change by establishing that more people have sought testing and by increasing anticipation of ARV demand

- Deepening knowledge of challenges and their impact: Information included in the antistigma bill was used by the House of Representatives Committee on Health to convince the National College of Aviation to issue a license to a graduate being denied her aviation license because of her HIV status. ${ }^{43}$

- Developing organisation-specific policies: The Nigeria Labor Congress, the umbrella body of 29 affiliate trade unions and 4 million union members, developed its policy on HIV and AIDS in 2003 on the basis of data presented to them at an ILO conference in $2002 .^{44}$

\footnotetext{
42 Interview with Mr. Obele, Spokesperson for Nigeria Network Religious Leaders Living with HIV/AIDS

${ }_{43}^{4}$ Interview with Mr. Jacob, Clerk of the House of Representatives Committee on Health

${ }^{44}$ Interview with Comrade Esther Ogunfowora, Project Coordinator, NLC TUK-UK Project
} 
- Targeting service provision: The NLC also relied on sero-prevalence data to support the Gikoi health care centre after realising that the Nyanya axis had the highest prevalence in the FCT. ${ }^{45}$

- Establishing resource allocation priorities: The Ogun state SACA recommended changes in resource allocation to the state legislature following the presentation of seroprevalence data. ${ }^{46}$

Numerous other examples of the use of data for policy recommendations and changes in interventions can be found. Pre-program assessments conducted by policy-makers and practitioners represent a common approach to generating policy and programme recommendations for service delivery.

Such examples illustrate the wealth of opportunities for research to improve outcomes in the national response. Demand for data far exceeded availability. Participants listed numerous examples of data and research requirements that remain unfulfilled. At the same time, it was clear that the available research and data have not been optimally utilised. The gap between demand and utilisation was not limited to the production of relevant data, but extended to the failure of communication between researchers and research users. Thus it is clear that evidence is failing to reach those who need it.

Moreover, there are numerous instances in which users rely on information that is not necessarily identifiable under any of the data generating and dissemination activities reported here. As one practitioner noted during the assessment, 'Policy-makers often use information, but they don't use it systematically and the information is not properly analyzed ${ }^{47}$. Another respondent put more credence in personal observation at the grassroots level than in the official sero-prevalence data. ${ }^{48}$ This observation demonstrates that policy-makers and practitioners are more likely to rely on data that accord with their own experience - even if such data are not systematically analysed. Hence they are willing to rely on non-systematic and non-analyzed data. Other facilitating factors are summarised below.

\footnotetext{
${ }^{45}$ Ibid. Ogunfowora

${ }^{46}$ Presentation by Ogun SACA Executive Secretary at GRIPP Assessment Workshop, Ibadan, August 2, 2010.

${ }^{47} \mathrm{Dr}$ Kola Oyediran, Measure Evaluation, personal communication.

${ }^{48}$ Interview with Comrade Esther Ogunfowora, NLC
} 


\section{Stakeholders}

The primary role of stakeholders in enhancing research utilisation, whether as researchers, policy-makers, practitioners and other research users, can be distilled into the following characteristics: time required to deliver results; language and medium of communication; knowledge focus; types of questions asked; and workplace ethos. 
Table 1: Stakeholder Roles in Data Utilisation

\begin{tabular}{|c|c|c|c|c|c|c|}
\hline Stakeholders/Roles & 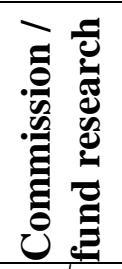 & 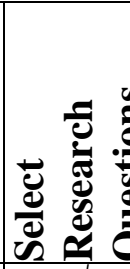 &  & 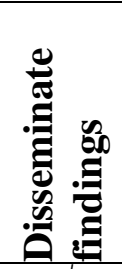 & 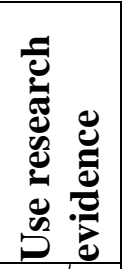 & 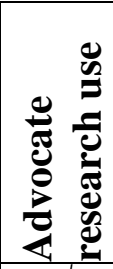 \\
\hline Academia, Research Institutes & $\sqrt{ }$ & $\sqrt{ }$ & $\sqrt{ }$ & $\sqrt{ }$ & $\sqrt{ }$ & $\sqrt{ }$ \\
\hline $\begin{array}{l}\text { Policy-makers (NACA and SACAs), Regulatory } \\
\text { Agencies }\end{array}$ & $\sqrt{ }$ & $\sqrt{ }$ & $\sqrt{ }$ & $\sqrt{ }$ & $\sqrt{ }$ & $\sqrt{ }$ \\
\hline Legislature & $\sqrt{ }$ & $\sqrt{ }$ & & & $\sqrt{ }$ & $\sqrt{ }$ \\
\hline Ministries, Departments, Agencies & $\sqrt{ }$ & $\sqrt{ }$ & $\sqrt{ }$ & $\sqrt{ }$ & $\sqrt{ }$ & $\sqrt{ }$ \\
\hline Civil Society Organisations & $\sqrt{ }$ & $\sqrt{ }$ & $\sqrt{ }$ & $\sqrt{ }$ & $\sqrt{ }$ & $\sqrt{ }$ \\
\hline International Development Partners & $\sqrt{ }$ & $\sqrt{ }$ & & & & \\
\hline Organised Private Sector & & & & $\sqrt{ }$ & $\sqrt{ }$ & $\sqrt{ }$ \\
\hline Community Leaders & & $\sqrt{ }$ & $\sqrt{ }$ & $\sqrt{ }$ & $\sqrt{ }$ & $\sqrt{ }$ \\
\hline Service Providers & $\sqrt{ }$ & $\sqrt{ }$ & $\sqrt{ }$ & $\sqrt{ }$ & $\sqrt{ }$ & $\sqrt{ }$ \\
\hline Service users & & $\sqrt{ }$ & & & $\sqrt{ }$ & $\sqrt{ }$ \\
\hline The Media & $\sqrt{ }$ & $\sqrt{ }$ & $\sqrt{ }$ & $\sqrt{ }$ & $\sqrt{ }$ & $\sqrt{ }$ \\
\hline Persons Living with or affected by HIV/AIDS & & $\sqrt{ }$ & $\sqrt{ }$ & & $\sqrt{ }$ & $\sqrt{ }$ \\
\hline
\end{tabular}

In the course of conducting the workshops and review for this assessment, a number of stakeholders made commitments to specific actions to improve data demand and utilisation. NACA pledged to a) ensure wide dissemination of national response information as a way of promoting data use; $b$ ) ensure incorporation of a data use plan in the next HIV M\&E plan; and c) strengthen supervision of states and feedback. NASCP similarly committed to a) conduct quarterly M\&E meetings at national and state levels; b) disseminate analyzed data to data providers quarterly; and c) improve information-sharing within NASCP. ${ }^{49}$

${ }^{49}$ NACA \& MEASURE Evaluation, 'Report of Workshops: Strengthening the Use of HIV and AIDS Information: Data Demand and Use Workshop, Lagos and Kaduna, February 2010. 


\section{BARRIERS TO RESEARCH UTILISATION}

Numerous structural, institutional and individual-level barriers were identified in the course of the workshop and assessment. These barriers limit the influence of research on policy and practice. The scaled list of barriers from the two workshops is provided in Annex III. The key barriers can be summarised as those related to:

- the gap between researchers, policy-makers and practitioners - and accentuated by structural challenges of Nigeria's federal system

- research outputs;

- organisational factors associated with the function of institutions, organisational cultures, and belief systems; and,

- Individual factors.

\section{Barriers related to the Gap between researchers, policy-makers and practitioners}

The perceived gap between data producers (researchers) and data consumers (policy-makers and programme managers) was rated by all stakeholders and workshop participants as the most significant barrier to research utilisation. Indeed it is a terminal barrier when seen in light of the important differences in characteristics and orientation between researchers on the one hand and policy-makers and practitioners on the other hand. Participants recommended a closer engagement between policy-makers and researchers to ensure that research focuses on current policy problems. Furthermore, data consumers requested that findings should be communicated in a format and language that would facilitate easy adoption by policy-makers.

\section{Barriers related to research output}

The scope and complexity of research can often make its incorporation difficult, since data generators build little capacity into analysis, storage and dissemination of findings in a userfriendly format. Policy-makers who are aware of the need for data are often constrained by failure to access relevant information that is credible and timely.

Other factors hindering data use include concerns over data quality, particularly where the data are generated by an external agency and the findings do not conform to the organisation's position on the issue. Another factor barring the use of data is authenticity of the source or 
process through which the data were obtained. Policy-makers by the nature of their work are sensitive to the credibility of the data to be used and may raise concerns about the political motivations or bias the data may represent. Furthermore, contradictory data are considered a hindrance rather than an opportunity to explore the issue further.

\section{Organisational and Political Barriers}

The lack of a learning or adaptive culture among government entities is a key organisational barrier to the use of data. Decision-making is often based on intuition or perception; one anecdote can easily become the basis for refutation of research results, and even policy.

In public sector agencies, bureaucratic organisational structure and procedures often hinder effective data use. Staff who are keen to incorporate relevant data from research into their work may often have to go through cumbersome procedures to gain access to data. Obtaining data can also be hindered by organisational policies which dictate that approval is obtained before data can be used, thus making the timely use of data difficult.

Policy-making in Nigeria is largely a closed process in which the citizenry play a limited role. There is little demand for accountability from Nigerians, which is reflected in the limited extent to which research findings or data are employed in policy formulation. In reality, policy-making is an inherently political process which prioritizes quick fixes and pre-set views over evidence and scientific investigation.

\section{Individual Facilitating Factors}

Examples of successful facilitation of the use of data were given during the workshop, mostly as anecdotal cases where barriers to data use were overcome. Examples included low PMTCT coverage in Nasarawa state prompting a re-allocation of resources to high-prevalence health centres, and the use of data for advocacy in support of the adoption of free MCH services. The free $\mathrm{MCH}$ example may also serve as a case of haphazardly applied data, where cost data were effectively discarded from the decision-making process. Other examples of 'facilitating' factors included the introduction of MARP indicators from NARHS and IBBSS surveys in the draft Kaduna state M\&E strategy and operational plan 2010-2015. Efforts at capacity building and resource support among SACA M\&E officers have resulted in simplified presentation of M\&E data in the form of pie charts and thematic maps. 


\section{Strategies to FACILITATE ReSEARCH UtILISATION}

\section{Strengthening interactions between researchers and research users}

Participants in the assessment encouraged the creation of opportunities to engage researchers, policy-makers and practitioners in a regular dialogue, which they believed would reduce the perceived divide between these groups. Such interactions might be scheduled for the purpose of discussing research questions and updating stakeholders on research activities and results. NACA, through the research and policy units, NARN and SACAs can convene such meetings as part of regular stakeholder forums. Also suggested were unscheduled interactions and exchanges to build trust and understanding among data producers and consumers through interpersonal relations. Good practice and/or "fail" fairs may also be an appropriate forum for producers and consumers to showcase good practices in research utilisation.

Formal institutional relationships may also play a facilitating role, through the establishment of research committees to host conferences, workshops and seminars. Such events may be technically focused like those sponsored by NARN and others more oriented to non-technical stakeholders. The engagement of research consumers in the research process would also benefit all parties, and would support both a utilisation agenda and an ethics mandate to fully inform and empower communities as participants in studies. Likewise, policy-makers can engage researchers more directly; NACA, for example, hosts researchers on sabbatical. This extends to the participation of researchers, policy-makers and programme managers on each domain's respective boards, steering committees, advisory councils, management committees, and working groups.

Normative approaches toward collaboration and engagement may also play a facilitating role in research utilisation by creating a positive nurturing environment and culture. Participants highlighted the role NACA has played in promoting research. Other institutions should likewise prioritise research internally and externally, leading by example as NACA has done.

\section{Knowledge dissemination channels and format}

While individual and institutional factors play an important role in knowledge production and dissemination, participants cited data presentation as equally important. Both channel and format should be considered, as well as who should be involved in the process. To the latter point, 
participants recognised the need for information producers and consumers to be involved in dissemination. However, none cited beneficiaries such as PLWHA or MSM as stakeholders to be engaged. Direct engagement with beneficiaries will require extraordinary dissemination events, media conferences, background briefings, and informational outreach visits to key policy and opinion makers. In general, assessment participants suggested easily accessible and understandable formats, customised to the audience. Examples of effective dissemination materials include policy briefs, and aides memoire containing short, bulleted summaries of key findings and clear policy recommendations and action points. For practitioners, executive summaries can provide a concise overview of the research problem, findings and actionable recommendations. For the general public, summaries of findings with real-life illustrative examples may provide a good mix of data with human interest to engage the mainstream media and the public. Research and policy initiatives can be enhanced through the endorsement of key opinion makers, including political and religious leaders, talk show hosts, columnists, and celebrities to disseminate key research findings.

\section{Adoption of a common evidence-base}

Researchers and practitioners alike cited the need to ensure that research topics are relevant, timely and useful. Relevance and, for that matter, what constitutes evidence, remains subjective however. Nigeria's new national research policy establishes four major areas of research consistent with the needs highlighted in the National Strategic Plan: basic clinical sciences, epidemiology, and public health; social and behavioural sciences; economics, operations research, and health systems; and policy, law, human rights, and governance. Further, the policy sets helpful parameters for acceptable quality standards for research.

While standards should engender greater confidence, research topics must still satisfy the needs of practitioners. Participants mentioned their respective priorities in terms of research topics, regardless of the particular research theme, with a good deal of commonality across functional roles. For instance, policy-makers and programme managers seek specific evidence regarding what works best, for whom, and what solutions are the most cost-effective. The facilitation of a dialogue around what constitutes evidence to whom, how to apply evidence, and how to shape relevant research questions would foster widespread confidence in research utilisation. 


\section{Addressing individual barriers to research utilisation}

Participants cited individual factors impeding utilisation as an important barrier. These barriers included skills and capacity, access to resources, and participation in the research process. Many times, these factors take the form of resource constraints such as limited access to computers and the internet. Likewise, participants indicated the need to equip policy-makers and practitioners with the knowledge and skills to participate in the research process and to use research findings. Such skills include basic training in research management and evaluation, operations research, data understanding and the application of research results. The assessment workshop session on data analysis demonstrated the need to conduct skills building among policy and program managers. Access and skills alone may not be sufficient without institutional rewards for individuals, such as incentives for using research outputs, and time allocation to review research findings as part of policy development or program delivery. Finally, to encourage champions within organisations, performance assessments might include targets on research utilisation linked to bonuses.

Some of the same incentives may be extended to the organisational level. Training and essential equipment might equally permit key organisations to equitably participate in the evidence creation and use process. Likewise, key executives in policy-making and programme management require support to effectively champion research utilisation within their institution. The assessment identified several prospective champions within the National Assembly, legislators, state AIDS control agencies and CSOs. 


\section{DISCUSSION}

\section{Alternative Models of Research Utilisation - Is there really a gap?}

The underlying premise of this report is the need to bridge the gap between research and policy. But is there a gap to be bridged? As Mendizabal states:

"The space between research and policy is crowded with players and relationships between them, not all researchers and policy-makers are equally connected the other members of the system. And this is one of the reasons why the impression of a gap remains so strong still." 50

The "research-to-use" divide can be characterised as the 'crowded middle', comprised of researchers, practitioners and development professionals already highly motivated and highly connected. Those outside of this network - policy-makers and their advisors - rely on their own networks to access and interpret information, particularly in many developing countries where informal channels are more accessible and trusted. One can argue that the tension between these two groups is healthy; one community does not exist in isolation from the other. Often actors alternate between spheres on a regular basis.

For as many examples of where the research-to-use gap exists, there are equally those instances where research has influenced policy and where researchers have influenced policy-makers. The perception of the research-to-use gap is reinforced by the unequal degree of connectedness in which many researchers find themselves. In reality some actors are better connected than others - either directly or through their personal or professional affiliations with organisations, networks and processes. The more connections an actor has, the greater the likelihood of making new and higher-value connections, commanding better knowledge of the system, and navigating the system more readily. In contrast, poorly networked researchers will have marginal gains from the systems and perceive their isolation as a gap to be filled.

\footnotetext{
${ }^{50}$ Mendizabal, E. (2011). Never mind the gap: on how there is no gap between research and policy and on a new theory. Onthinktanks.org. Accessed 28/7/2011. http://goo.gl/vMKMp
} 


\section{Focus on research, not on researchers}

The literature and debate on 'bridging research and policy' often confuses the researcher with research and the policy-maker with policy. An instrumental bias permeates the research-to-use arena, whereby researchers and practitioners alike are driven to find a particular piece of research or example of policy-influence which will make the difference in terms of impact. In part, this imperative is driven by a competitive consultancy business model and a communications narrative focused on perceived audience needs. In the process, we fail to understand the complex system of policy formulation and decision-making. The failure of policy-makers to use research assumes the policy-maker agrees with findings put forth. Policy outcome may have less to do with the quantity and strength of evidence than with the worldview, organisational milieu, and personal networks of the policy-maker. More often than not, policy-makers already base their policy decisions on some research, usually relying on trusted networks based on long-standing relationships between research and policy communities. Ultimately a policy maker interprets evidence depending on individual and institutional development narratives, analytical frameworks, and values.

Rather than focus on the role of researchers in policy-making, we should ensure that research plays a value-added role. Shifting the focus of research utilisation onto the political context and its respective audiences will help to delineate maps of knowledge production and utilisation along with strategies to engage the various actors in priming the system. Attention should shift beyond the skills and competencies of individual researchers and centres towards a better understanding how and why research influences policy and policy-makers. Assistance, then, should be directed at the knowledge sector as a whole.

\section{Make maps, not bridges}

Navigating the complex systems of knowledge production and use requires a clear view of the networks, processes, and organisations which comprise such systems. To this end, the knowledge management should:

- Focus on research and policy rather than researchers and policy-makers;

- Understand the nature of the research and policy processes, and the relations between them; and 
- Understand the role that information density plays in facilitating the use of knowledge in policy"

The myth of a research/policy gap distorts our understanding of the relationship between researchers and policy-makers. Rather than instrumental strategies to bridge this gap, the focus should be on fostering the institutional interactions between researchers and policy-makers.

\section{More must be better}

The role evidence plays in the policy process depends largely on the political context, sector or policy issue being addressed, and the organisational context of knowledge producer and consumer. In some circumstances (such as over highly contentious issues), the active and direct engagement between researcher and policy-maker may be less desirable. There are numerous indirect channels for evidence to influence practice, such as scientific journals, popular press, government scientists, scientific NGOs, think tanks, universities, schools, etc. Influence by researchers in the policy process depends less on the engagement strategy and more on the policy context, length of policy process, who drives it, and involvement of interest groups. ${ }^{51}$ No empirical evidence exists indicating investments in communications initiatives leads to more influence on policy processes or practice. ${ }^{52,53,54}$ Communication strategies may increase the visibility of a researcher or donor, but the net outcome is not yet determined to be durable.

\section{It's all about density}

The HIV and reproductive health arena in Nigeria has a high concentration of researchers and policy-makers; nonetheless the perception exists of isolation and alienation among individual actors as well as fragmented organisational structures. What is important is density of knowledge

\footnotetext{
${ }^{51}$ Rich, Andrew. (2004) Think Tanks, Public Policy, and the Politics of Expertise. Cambridge University Press.

${ }^{52}$ Shaw, B., Cheater, F., Baker, R., Gillies, C., Hearnshaw, H., Flottorp, S., et al. (2005). Tailored interventions to overcome identified barriers to change: Effects on professional practice and healthcare outcomes (Review). Cochrane Database of Systematic Reviews, 3, Art. No. CD 005470. DOI: 10.1002/14651858.CD 005470.

${ }^{53}$ Grimshaw, J. M., Shirran, L., Thomas, R., Mowatt, G., Fraser, C., Bero, L. A., et al. (2001). Changing provider behavior: An overview of systematic reviews of interventions. Medical Care, 39(8, Suppl. 2), II2-II-25.

${ }^{54}$ Grimshaw, J. M., Thomas, R. E., MacLennan, G., Fraser, C., Ramsey, C. R., Vale, L., et al. (2004). Effectiveness and efficiency of guideline dissemination and implementation strategies. Health Technology Assessment, 8(6). Retrieved March 7, 2007, from http://www.hta.ac.uk/fullmono/mon806.pdf
} 
production that increases the linkages between researchers and policy-makers not the instrumental connectedness between research and policy. The creation of highly dense knowledge production favours quality and quantity of research over strategic placement or targeted research. This may translate into encouraging competition in knowledge production, using intermediaries to place research products, and measuring impact at a systems level.

Decisions take place within political contexts and specific policy processes. Density of knowledge in those contexts may be high if ample information is available from a number of competing and complementary sources; and low if little data is available from limited sources. One-sided or unconfirmed data, even if plentiful, does not constitute high density. At the same time, policy contexts may have high or low political interest; with high-political-interest contexts garnering greater participation and representation from multiple sectors of society and lowinterest contexts remaining largely hidden from view. 


\section{RECOMMENDATIONS}

The findings of this assessment reflect the opinions of the participants and researchers who engaged in a reflexive dialogue. The objective of the exercise was to confirm external observations about barriers to data utilisation in Nigeria and to propose a refined set of observations and suggestions for moving forward. In the discussion above, we challenged some of the commonly held beliefs related to barriers to utilisation. In part, this reflects a contrarian view of long-standing efforts to promote data utilisation with ineffectual strategies. However, it would be counter-productive to discard the established data utilisation promotion efforts as related to skills-building, infrastructure, and targeting of research results. The previous discussion and following recommendations hope to stimulate a paradigm shift in how the Nigerian government, civil society, and international development partners approach research utilisation for the next generation.

1. Take a systems- or sector-wide approach to knowledge generation:

A broad approach recognises the interconnectedness between research and utilisation at an institutional level without trying to pick winners. This avoids a magic bullet mentality which rarely translates to policy change.

2. Increase overall generation of knowledge:

An improvement in research quality and capacity to produce rigorous research will contribute to the maintenance of policy relevance.

3. Facilitate knowledge sharing through specialised media publications, individual journalistic investigation, and increased spaces for policy debate:

Specialised channels should be harnessed to drive the overall level of knowledge utilisation such as cultivating relevant debates within a community of practice and Opening them to public scrutiny; strengthening the relations between policy-making bodies, political parties, and local think tanks; and developing analytical skills within policy-making bodies.

4. Develop a research utilisation strategy actionable at the sub-sectoral level to target policy-maker perceptions and practice of research application in specific contexts: Based on informed use of strategic research, a target research utilisation strategy should be harnessed to a demonstrable impact on the state of practice in a particular sub-sector. 
For example, the application of operational research studies to introduce innovations in ARV therapy for sero-discordant couples, mother-infant tracing to reduce loss-to-follow for PMTCT, and the engagement of private providers to reach hidden and hard to reach populations such as MARPS.

5. Map out the knowledge production and consumption systems in a given sector and country:

Deploy tools such as social network analysis ${ }^{55}$ and net-map ${ }^{56}$ to better understand the political economy of knowledge production and focus communication channels and products on key facilitating institutions and individuals.

${ }^{55}$ Clark, L. (2006) Network Mapping as a Diagnostic Tool Manual. Centro Internacional de Agricultura Tropical (CIAT). La Paz, Bolivia.

${ }^{56}$ Schiffer, E. (2007). The Net-Map Toolbox. International Food Policy Research Institute. Washington, DC. 


\section{ANNeX I: Summary OF MeASURE Workshop}

\section{Strengthening the Use of Data to Inform HIV/AIDS Policy and Practice in Nigeria}

\section{$\underline{\text { Introduction }}$}

Getting Research into Policy and Practice (GRIPP) is an approach, sponsored by the Population Council and anchored by the Enhancing Nigeria's Response (ENR) to HIV and AIDS Programme, which aims to identify why research outputs are not informing decisions and practice related to HIV and AIDS programming in Nigeria. The GRIPP approach will help strengthen existing models on data demand and information use in HIV and AIDS programming in the country. MEASURE Evaluation works in Nigeria to strengthen the demand, collection, analysis and use of data through the application of Data Demand and Use (DDU) tools, approaches, and curricula. MEASURE Evaluation's DDU tools and approaches and the GRIPP approach identified key issues in Nigeria that will be addressed through a national strategy to enhance the mainstreaming of research and other data into policy and practice in the national response to HIV and AIDS. The National Agency for the Control of AIDS (NACA), through its coordinating mandate and using a consultative process, has formed a reference group comprising MEASURE Evaluation, ENR and NACA, to develop the strategy.

Two series of workshops were held with participants from Akwa-Ibom, Lagos, Ogun, FCT, Benue, Kaduna and Nasarawa States. Participants were carefully selected to include the following professional groups of about 6 persons from each state:

- Policy-makers and managers with key executive roles in the state response (SACA executive secretaries/SPT managers)

- SACA officials with responsibility for M\&E

- Executives (one each) from the State Planning Commissions and Budget Offices who have responsibility for preparing resource allocation proposals

- Leading researchers based in a university or research institute located in the state

- Chairman of the House of Assembly Committee on HIV/AIDS

- Policy-makers, research and M\&E executives at NACA, FMOH and FME. 
The assessment workshops were held in Ibadan, Oyo state. NACA moderated the meeting and MEASURE Evaluation led the facilitation of the technical sessions, while ENR through Population Council managed the logistics and other matters regarding the workshop. Two academicians, Professors Gbenga Sunmola and Idowu Olayinka from the University of Ibadan, provided technical assistance. The first series of assessment workshops was held August 2-4, while the second series was held from August 5-7, 2010.

\section{Goal and Objectives of the Assessment Workshop}

The goal of the assessment was to explore how research can shape policy and practice in Nigeria, using existing tools. Its purpose is to prepare and help roll out a draft data demand and use strategy that outlines the content required, format and methods by which such content should be presented and the tools for promoting information use.

\section{The objectives are:}

- To identify barriers and facilitating factors in data demand and information use at national and sub-national levels

- To generate action plans that will inform the proposals, examples, and recommendations to incorporate in a draft strategy for strengthening and monitoring demand for data and information use at national and sub-national levels

- To promote a commitment to data demand and information use at all levels

The immediate outcomes of the workshop were:

- The availability of raw material resources (data) for the development of a strategy to address the gaps in the use of data for decisions in HIV and AIDS programming.

- Identification of barriers, constraints and facilitating factors related to data use.

- Development of data use action plans for key sectors in HIV programming in Nigeria.

- Recommended intervention areas to address data use constraints.

- Identification of examples of good data use practices in HIV programming.

\section{Methodology}

The technical sessions were conducted through presentations and group work. MEASURE Evaluation tools were used throughout the technical sessions. The technical part of each training 
session began with a PowerPoint presentation on the subject matter of the session before breakout into groups. The first session was grouped according to federal and states. The states were further divided into SACAs, SMOH and NGOs. This was done in anticipation that the groups will be too many to manage if divided according to functional areas. During the second session however, the groups were divided based on functional groups as follows: Ministries, Departments and Agencies (MDAs), Budget and Planners, Academia (comprising Research Institutions and Federal Medical Centres), Civil Society Organisations (CSOs), SACAs, SMOH and Legislators. Using this approach, each group was able to draw experiences and illustrations that were relevant to group members, thus coming up with richer and more helpful outputs.

\section{Highlights of Technical Sessions}

\section{Experience from States on Information Use}

The technical session for each training session started with a presentation from one of the states on how HIV data is collected, analysed, shared and used. Participants also described the information flow in the state. Participants from other states discussed the presentation and described practices in their states. The objective of the session was to encourage identification of best practices on data gathering and information use among states. The session helped to inform facilitators of what was available in terms of the subject matter across the participating states.

\section{From Research to Policy}

Professor Olayinka from the University of Ibadan who enumerated the steps in research and described how to translate research efforts into policy. This session was aimed at providing orientation on the research component of HIV data.

\section{Data Use Concepts}

This session began with a presentation on the concepts of data demand and use and MEASURE Evaluation's approaches to strengthening the demand for and use of data. The presentation was punctuated by brief discussion questions as a background to a group work on identification of stakeholders. From the discussions that were held after the presentation it was obvious that organisations represented at the workshop do not have data use plans and do not use data as discussed in the presentation. They all resolved to provide information to their stakeholders for decision-making. 


\section{Identification of Stakeholders}

During the first session of the workshop, participants were divided into states, federal and Civil Society organisations, while for the second session participants were divided along functional lines into seven groups ranging from data producers to politicians. They all identified the stakeholders in their programs and justification for the use of information by their respective stakeholders.

\section{Understanding Information Flow and Information Use Mapping}

A short presentation on information flow preceded group work on information use mapping. Participants were then introduced to a MEASURE Evaluation tool, referred to as the Information Use Map. The map allows a user to describe the existing flow of health information to identify opportunities for improving its use, identify gaps and opportunities for using information, identify opportunities for additional feedback mechanisms, and identify points where analysis and data could support programmatic decision-making.

The participants were then divided into groups to develop Information Use Maps to visually describe the flow of information in their organisation. Some participants noted that this was a unique opportunity to consider how things are really done as opposed to how the data and information are supposed to be reported. Each was asked to present the map during plenary. The maps were used to inform the next session on barriers to data use.

\section{Barriers to Using Data to Inform Decision-making}

Following a presentation on factors that may hamper the use of data, groups reconvened to identify and discuss barriers to using information at different levels within their organisation and among the groups they supervise. Participants were asked to rank the barriers based on their perceived order of significance. The results of the ranked barriers to data use are presented in Annex III.

\section{Plan for Addressing Barriers to Using Data}

Groups developed a plan for addressing the key barriers to data use which they had earlier identified. The groups prioritised at least four barriers from the lists and developed solutions to them. These solutions are documented in a plan to address barriers to data use and could be applied in their respective organisations. The plan defines steps to implementing these solutions, 
persons or groups responsible, and general timelines for implementing the plan. Groups were later asked to mention some of the factors facilitating data use in their organisations.

\section{Data Analysis and Interpretation}

Groups were provided with simulated data on HCT, PMTCT and ART and were asked to respond to questions about the data. This led to a group exercise of basic calculations, analysis and interpretation in order to answer these questions. Groups were divided based on the thematic areas in the HIVandAIDS interventions mentioned above. Groups presented their work at the plenary session, with all participants making comments on additional action that can be taken by the local management on the data. The group work prompted interesting discussions within the small groups as well as at the plenary session.

\section{Developing an Action Plan on Linking Decisions with Data}

A brief presentation on linking data with important decisions was made using the MEASURE Evaluation tool. A template of the tool was then presented to each group for them to develop ways to link decisions in their organisation with data.

\section{Commitments to Data Use}

Each group was asked to develop three actionable steps they will carry out with regard to data use within their organisation in the next three months. The objectives of the session were to help participants to make definite commitments to data use and to apply their new skills gained from the workshop.

\section{Next Steps}

Carry out key informant interviews: Population Council will conduct a validation exercise using qualitative tools such as key informant interviews to ascertain the perspectives of policymakers who were not able to attend the workshop.

Strategy Development and Dissemination Process. The findings of the assessment will provide the building blocks for developing the envisaged DDU strategy. A call for this action will be carried out by NACA with appropriate stakeholders. 
Presentation of the report of the workshop to NACA. It is expected that this report, which contains the process for the workshop, will form part of the larger report that will be jointly submitted to NACA by MEASURE Evaluation and Population Council.

Expansion to other states: Measure Evaluation and Population Council will identify mechanisms and opportunities for extending this workshop to other states in Nigeria. 


\section{Measure Workshop Agenda}

\begin{tabular}{|c|c|c|}
\hline \multicolumn{3}{|l|}{ Day 1} \\
\hline Time & Activities & Tools \\
\hline 8.30 & Registration & \\
\hline 9.00 & $\begin{array}{l}\text { Welcome } \\
\text { Opening prayer } \\
\text { Introductory remarks } \\
\text { NACA, Host SACA, MEASURE, ENR/DFID }\end{array}$ & \\
\hline 10.00 & Tea Break & \\
\hline 10.30 & $\begin{array}{l}\text { Begin Technical Agenda } \\
\text { Kaduna or Ogun to present on process of generating/using data } \\
\text { from point of service to decision level (including type of } \\
\text { information, how it is transmitted, who is involved and what kind } \\
\text { of decision) }\end{array}$ & \\
\hline & $\begin{array}{l}\text { Session 1: How data can be used for program management, } \\
\text { implementation and decision-making }\end{array}$ & \\
\hline 10.45 & $\begin{array}{l}\text { Data Use Overview: How data can be used for program } \\
\text { management, implementation and decision-making } \\
\text { Presentation describing data use concepts and general discussion of } \\
\text { experiences }\end{array}$ & \\
\hline 11.15 & $\begin{array}{l}\text { Group Work: Identifying stakeholders and previous uses of } \\
\text { information } \\
\text { Small groups will discuss and document key stakeholders and ways } \\
\text { the organisation uses data }\end{array}$ & $\begin{array}{l}\text { Group work on } \\
\text { Flip Charts }\end{array}$ \\
\hline & Session 2 & \\
\hline 11.45 & $\begin{array}{l}\text { Understanding Data and Information Flow } \\
\text { Presentation on understanding information flow and the } \\
\text { information use map }\end{array}$ & \\
\hline 12.15 & $\begin{array}{l}\text { Group Work: Organisational Data Flow and Information Use } \\
\text { Mapping } \\
\text { Small groups will examine the flow of data in their organisations } \\
\text { using the Information Use Map. Groups will complete an } \\
\text { Information Use Map for their organisation and will identify gaps } \\
\text { and opportunities for improving data use }\end{array}$ & $\begin{array}{l}\text { Reading: Binder - } \\
\text { Information Use } \\
\text { Map } \\
\text { Information Use } \\
\text { Map }\end{array}$ \\
\hline 1.00 & Lunch & \\
\hline 2.00 & $\begin{array}{l}\text { Round Robin } \\
\text { Groups present their Information Use Maps to two other groups, } \\
\text { take questions, and receiving feedback from other groups to } \\
\text { improve their maps and analyses }\end{array}$ & $\begin{array}{l}\text { Information Use } \\
\text { Map }\end{array}$ \\
\hline & Session 3: Barriers and Facilitating Factors in Data Utilisation & \\
\hline 2.30 & $\begin{array}{l}\text { Barriers and facilitating factors in data demand and use } \\
\text { Presentation defining barriers and facilitating factors in data use }\end{array}$ & \\
\hline
\end{tabular}




\begin{tabular}{|l|l|l|}
\hline 3.00 & $\begin{array}{l}\text { Group Work: Across organisations } \\
\text { Small groups will discuss and document barriers and facilitating } \\
\text { factors in using information for decision-making and program } \\
\text { implementation. They will then present back to plenary and will } \\
\text { then move into different small groups for the next exercise. }\end{array}$ & $\begin{array}{l}\text { Reading: Binder - } \\
\text { Assessment } \\
\text { Data } \\
\text { Constraints }\end{array}$ \\
\hline $\begin{array}{l}\text { Group Work: Within organisations } \\
\text { Small groups will convene by organisation. Using their } \\
\text { organisational Information Use Maps and the lists of barriers } \\
\text { produced in the previous session, the group will develop a list of } \\
\text { barriers and facilitators to data use that is relevant to their } \\
\text { organisation. The group will then prioritize their list of barriers and } \\
\text { facilitators }\end{array}$ & $\begin{array}{l}\text { Developed Group } \\
\text { Map }\end{array}$ \\
\hline 5.00 & Wrap-up and Announcements & \\
\hline Facilitators meeting & \\
\hline
\end{tabular}

\begin{tabular}{|c|c|c|}
\hline \multicolumn{3}{|l|}{ Day 2} \\
\hline Time & Activities & Tools \\
\hline 8.30 & Opening prayer, Summary of Day 1 & \\
\hline & Session 4: Developing Action Plans to Facilitate Data Use & \\
\hline $8: 45$ & $\begin{array}{l}\text { Presentation on Developing Action Plan for Linking Decisions with } \\
\text { Data }\end{array}$ & \\
\hline 9.15 & $\begin{array}{l}\text { Group Work } \\
\text { Group work on how to develop Action Plan for linking Decisions } \\
\text { with Data }\end{array}$ & $\begin{array}{l}\text { Action plan for } \\
\text { data use template } \\
\text { and Stakeholders } \\
\text { engagement tool } \\
\text { in the binder }\end{array}$ \\
\hline 10.15 & Tea Break & \\
\hline $10: 45$ & Group presentation of Action Plans at the Plenary & $\begin{array}{lr}\text { Data Use } & \text { plan } \\
\text { developed } & \text { by } \\
\text { groups }\end{array}$ \\
\hline & Session 5: Analysing and Interpreting Data and Information & \\
\hline $11: 30$ & $\begin{array}{l}\text { Presentation on basic analyses used in reporting and program } \\
\text { improvement and tips for interpreting data }\end{array}$ & \\
\hline 1:00 & Lunch & \\
\hline 2:00 & Group work on data analysis and interpretation & $\begin{array}{l}\text { Presentation data } \\
\text { for Groups to use }\end{array}$ \\
\hline 4:00 & Group presentation of data analysis and interpretation at plenary & $\begin{array}{l}\text { Charts produced } \\
\text { by groups }\end{array}$ \\
\hline 5.00 & Wrap-up and Announcements & \\
\hline
\end{tabular}

\begin{tabular}{|l|l|l|}
\hline \multicolumn{2}{|l|}{ Day 3} & \\
\hline Time & Activities & \\
\hline 8.30 & Opening prayer, Summary of Day 2 & \\
\hline
\end{tabular}




\begin{tabular}{|c|c|c|}
\hline & $\begin{array}{l}\text { Session 6: Providing feedback and strengthening feedback } \\
\text { mechanisms }\end{array}$ & \\
\hline $8: 45$ & $\begin{array}{l}\text { Presentation about the importance of providing feedback as a key } \\
\text { component of the information flow to ensure information is used by } \\
\text { decision-makers }\end{array}$ & \\
\hline 11.15 & $\begin{array}{l}\text { Group Work } \\
\text { (Organisations to bring their feedback reports and descriptions of } \\
\text { their feedback mechanisms to the workshop) Small groups will } \\
\text { work on a series of steps to help review and strengthen the } \\
\text { organisation's feedback mechanism }\end{array}$ & $\begin{array}{l}\text { Feedback barriers } \\
\text { template }\end{array}$ \\
\hline 12.00 & $\begin{array}{l}\text { Group Report } \\
\text { Groups will present newly proposed feedback mechanisms, } \\
\text { highlighting new indicators or data needs and outlining guidance to } \\
\text { staff for providing feedback }\end{array}$ & $\begin{array}{lr}\text { Feedback } \\
\text { mechanism plan } \\
\text { developed } \\
\text { groups }\end{array}$ \\
\hline 1.00 & Lunch & \\
\hline & Session 7: Finalizing Action Plans & $\begin{array}{l}\text { Data use action } \\
\text { plan developed by } \\
\text { groups }\end{array}$ \\
\hline 2.00 & $\begin{array}{l}\text { Group Work } \\
\text { Groups finalize their action plans for data use }\end{array}$ & \\
\hline 3.30 & $\begin{array}{l}\text { Group Commitments } \\
\text { Groups identify } 3 \text { things they can do in the next } 3 \text { months }\end{array}$ & $\begin{array}{l}\text { Commitment plan } \\
\text { from all groups }\end{array}$ \\
\hline 4.00 & Parking lot, Q\&A, Wrap-up & \\
\hline
\end{tabular}

\section{ANNEX II: WORKSHOP PARTICIPANTS}

\begin{tabular}{|r|l|l|l|}
\hline \multicolumn{1}{|c|}{ S/N } & NAME & DESIGNATION & ORGANIZATION \\
\hline 1 & Lateef O.M & Rep D. G. Budget & $\begin{array}{l}\text { Ogun Bureau of Management } \\
\text { and Budget }\end{array}$ \\
\hline 2 & Olukoga Gabriel & Rep Perm Sec. & Ministry of Health Abeokuta \\
\hline 3 & Obasesam Etowa & M \& E TA & ENR \\
\hline 4 & Emmanuel Udoh & SPM - AKS & FME \\
\hline 5 & Nnorom Enakeme & CEO & FNR \\
\hline
\end{tabular}




\begin{tabular}{|c|c|c|c|}
\hline 6 & Vivien Ukaka & M \& E PHI & PHI \\
\hline 7 & Sam Unom & Consultant & Spade Consulting Ltd \\
\hline 8 & Kemi Odukoya & P.H. Physician & LUTH \\
\hline 9 & Francis Agbo & $\mathrm{PPO}$ & NACA \\
\hline 10 & Mrs. Adama A. P. & $\begin{array}{c}\text { Project } \\
\text { Manager HIV/AIDS }\end{array}$ & FMWASD \\
\hline 11 & Joseph Udo Inyang & $\begin{array}{c}\text { Director } \\
\text { Program Monitoring }\end{array}$ & $\begin{array}{l}\text { Ministry of Economic } \\
\text { Development }\end{array}$ \\
\hline 12 & Oso Felix & $\begin{array}{c}\text { HIV/AIDS } \\
\text { Program Manager }\end{array}$ & CCL Ijebu \\
\hline 13 & Anenih James & Research & NACA \\
\hline 14 & Gbenga Sunmola & Research & NACA \\
\hline 15 & Solomon Adebayo & SPCS & ENR \\
\hline 16 & Funmi Jaja & AD/MLS & NASCP/FMOH \\
\hline 17 & Mafo Yakubu & Programs & NACA \\
\hline 18 & Enenche Ene & $M \& E$ & NACA \\
\hline 19 & Martin Akpan & Chairman & AKSACA \\
\hline 20 & Margaret Edet & $\mathrm{CPO}$ & $\begin{array}{l}\text { National Population } \\
\text { Commission }\end{array}$ \\
\hline 21 & Dr. Fatungase & Consultant & OOUTH \\
\hline
\end{tabular}




\begin{tabular}{|c|c|c|c|}
\hline 22 & Faweya Femi & HIV/Technical & ENR \\
\hline 23 & Aniefiok Ekwere & $\mathrm{M} \& \mathrm{E}$ & AKSACA \\
\hline 24 & Sola Olufade & SPM Ogun & ENR \\
\hline 25 & Standfast Amonia Moreen & $\begin{array}{l}\text { PM/Head } \\
\text { HIV Unit }\end{array}$ & FMYD \\
\hline 26 & Ogunniyi Anthony & $\mathrm{M} \& \mathrm{E}$ & CCL, Ijebu \\
\hline 27 & Adeonojobi Adedamola & $M \& E$ & OGSACA \\
\hline 28 & Samson Bamidele & Resident Advisor & MEASURE Evaluation \\
\hline 30 & Araoye Segilola & Asst Director & NASCP/FMOH \\
\hline 31 & Dr. Segun Oyedeji & SPM & ENR \\
\hline 32 & Noma Daniel & $\mathrm{PO}$ & Population Council \\
\hline 33 & Dr. Ranti Oladeinde & CEO & OGSACA \\
\hline 34 & Andrew Karlyn & Associate & Population Council \\
\hline 35 & Onoriode Ezire & $\begin{array}{c}\text { M\&E } \\
\text { Research Manager }\end{array}$ & ENR/SFH \\
\hline 36 & Ezechukwu Chidozie & Strategic Planning & NACA \\
\hline 37 & Sylvia Adebajo & Associate & Population Council \\
\hline 38 & Idowu Olayinka & Professor & University of Ibadan \\
\hline 39 & Juliana Joseph & D M\&E & KADSACA \\
\hline
\end{tabular}




\begin{tabular}{|c|c|c|c|}
\hline 40 & Ocheme Yusuf Friday & M\&E Officer & FMWASD \\
\hline 41 & Ameh Julius Aromeh & $\begin{array}{c}\text { CEO } \\
\text { HIV \& AIDS }\end{array}$ & FME-HIV \& AIDS \\
\hline 42 & Uladi T. Amos & $\begin{array}{l}\text { HIV/AIDS } \\
\text { Coordinator }\end{array}$ & DACA Kaduna \\
\hline 43 & IIiya Magaji & CEO & YOTASCID Kaduna \\
\hline 44 & Esther Oigoga & Ex. Director & OCAG \\
\hline 45 & Odeh Roselyn & SPM Benue & ENR Benue \\
\hline 46 & Manasseh M. Katsa & M \& E Officer & YMCA, Lafia \\
\hline 47 & Farouk Musa & SPM & ENR \\
\hline 48 & Dr Mark D. Anthony & DICS/PM & KADSACA \\
\hline 49 & Umar Adamu & M\&E TA & ENR \\
\hline 50 & Adams John & $M \& E$ & SASCP Kaduna \\
\hline 51 & Gabriel Ameh & DPRS & SMOH MKD \\
\hline 52 & Janet S. Garba & $\begin{array}{c}\text { Project } \\
\text { M\&E Assistant }\end{array}$ & FMOYD \\
\hline 53 & Amade Sam & M\&E TA & ENR \\
\hline 54 & Iember Iorkyosu & $\mathrm{BSP}(\mathrm{MKD})$ & $\mathrm{CPO}$ \\
\hline 55 & Kogi A. Joseph & $\mathrm{M} \& \mathrm{E}$ TA & ENR \\
\hline 56 & Andrew Ikuesan & SSTA & ENR \\
\hline
\end{tabular}




\begin{tabular}{|c|c|c|c|}
\hline 57 & Ibrahim Azara & Project Manager & NASCA \\
\hline 58 & Jibril Abdullahi & & MoEp Kad \\
\hline 59 & Jafaru H. Tsaku & DOB & MOF-Lafia \\
\hline 60 & Inuwa B. Jmiwho & $\begin{array}{l}\text { AD/Programme } \\
\text { Coordinator }\end{array}$ & $\mathrm{NPC}-\mathrm{Hq}$ \\
\hline 61 & Abdulsamad Salihu & SPM & ENR NAS \\
\hline 62 & Ahmed Ibrahim & Director Planning & NSPC \\
\hline 63 & Dr Stephen Bature & Obst \& Gyn & ABUTH Zaria \\
\hline 64 & Grace A. Wende & ES & BENSACA \\
\hline 65 & Sati Kenchia & M\&E HBC & ADDS MILO \\
\hline 66 & Amiseh Jane & $\begin{array}{l}\text { Budget } \\
\text { MoF Dept. }\end{array}$ & $\mathrm{MoF}$ \\
\hline 67 & Esala S. Ashenanye & DPRS & MoH Nasarawa \\
\hline 68 & Aisha H. Kasim & $\mathrm{M} \& \mathrm{E}$ & NASACA \\
\hline 69 & Osayi Yahaya & $M \& E$ & NASH \\
\hline 70 & Ruth Oppa & $\begin{array}{l}\text { DDL/M } \\
\text { Sec Health }\end{array}$ & KDHA \\
\hline 71 & Bayi S. Dauda & HSCBO & MOEP \\
\hline 72 & Charles Hemba & $\begin{array}{c}\text { M\&E/ } \\
\text { Data Analyst }\end{array}$ & Ben SACA \\
\hline
\end{tabular}




\begin{tabular}{|r|l|c|l|}
\hline 73 & Oluremi A. F. & Radio Nigeria & FRCN \\
\hline 74 & Samson Adebayo & SFH & SFH \\
\hline 75 & Alonge Sunday & Researcher & NISER \\
\hline 76 & Damola Ogunbowale & Programme Manager & ENR \\
\hline 77 & Mafo Yakubu & M\&E & NACA \\
\hline 78 & Anenih James & Research & NACA \\
\hline 79 & Enenche Ene & M\&E & NACA \\
\hline 80 & Apera Iorwakwagh & Social & Population Council \\
& & Franchise Manager & \\
\hline 81 & Dr Issa B. Kawu & SMO & FMoH \\
\hline
\end{tabular}

\section{ANNEX III: BARRIERS TO DATA UTILISATION}

$\begin{array}{lr}\text { Barriers Identified } & \text { Total }\end{array}$

\begin{tabular}{ll} 
& Cited \\
\hline Communication gap between researchers and policy-makers & 82 \\
\hline Lack of ownership of data generation process & 76 \\
\hline Lack of sustainability in data use for policy-making & 74 \\
\hline
\end{tabular}

Frequent change of key officers creates gap in continuity and causes delay in data 73 use

\begin{tabular}{ll}
\hline Misappropriation of funds meant for data dissemination and use & 70 \\
\hline Resistance to change to procedures or processes, technology and use of data & 70 \\
\hline States are at liberty not to use research outcomes & 68 \\
\hline Lack of political interest by policy-makers & 67 \\
\hline Political interference on issues around HIV and AIDS & 65 \\
\hline Little emphasis on research & 65 \\
\hline Low political commitment to use data for decision-making & 63 \\
\hline Poor appreciation of data by decision-makers & 63 \\
\hline Inadequate funding to address data management activities & 61 \\
\hline No policy on data storage, interoperability, harmonisation and use & 61 \\
\hline Poor infrastructure for data use (computer systems, storage facilities, space, & 60
\end{tabular}


buildings, data bank etc)

\begin{tabular}{ll}
\hline Limitation of NNRIMS to meet the data needs of policy-makers & 58 \\
\hline $\begin{array}{l}\text { Organisational culture of bureaucracy not conducive to evidence based decision- } \\
\text { making and utilisation of data (leading to concealment) }\end{array}$ & 57 \\
\hline Paucity of skilled personnel for data management and analysis & 57 \\
\hline No clear understanding of NNRIMS by program managers and policy-makers & 56 \\
\hline $\begin{array}{l}\text { Poor understanding of issues surrounding HIV/AIDS program monitoring and } \\
\text { evaluation }\end{array}$ & 55 \\
\hline Poor access to data in a usable format & 52 \\
\hline Low capacity of data generators and users to interpret data & 52 \\
\hline Poor reporting systems (no clear channel of communication of information) & 52 \\
\hline Data not disseminated in timely manner & 50 \\
\hline Disaggregation of budgetary line items for data generation and use & 50 \\
\hline $\begin{array}{l}\text { Inadequate technical capacity of program managers to make informed decision with } \\
\text { data }\end{array}$ & 48 \\
\hline Challenges to interpretation of multiple data sources (with disparity in results) & 45 \\
\hline Inadequate skills of program managers to present data in usable format & 43 \\
\hline Low confidence in data quality & 38 \\
\hline Data not relevant to needs of decision-makers & 32
\end{tabular}




\section{List of Contributors}

\begin{tabular}{|r|l|l|}
\hline \multicolumn{1}{|l|}{ S/N } & NAMES & ORGANIZATION \\
\hline 1 & Sam Unom & Consultant \\
\hline 2 & Samson Bamidele & Measure Evaluation \\
\hline 3 & Kayode Odugbemi & NACA \\
\hline 4 & Prof Gbenga Sumola & NACA \\
\hline 5 & Mr. Onoriode Ezire & ENR/SFH \\
\hline 6 & Solomon Adebayo & ENR/Options \\
\hline 7 & Dr. Andrew Karlyn & ENR/Population Council \\
\hline 8 & Dr. Sylvia Adebajo & ENR/Population Council \\
\hline 9 & Apera Iorwakwagh & Population Council \\
\hline 10 & Dr. George Eluwa & ENR/Population Council \\
\hline 11 & Segun Sangowawa & Population Council \\
\hline 12 & Dr. Babatunde Ahonsi & \\
\hline
\end{tabular}




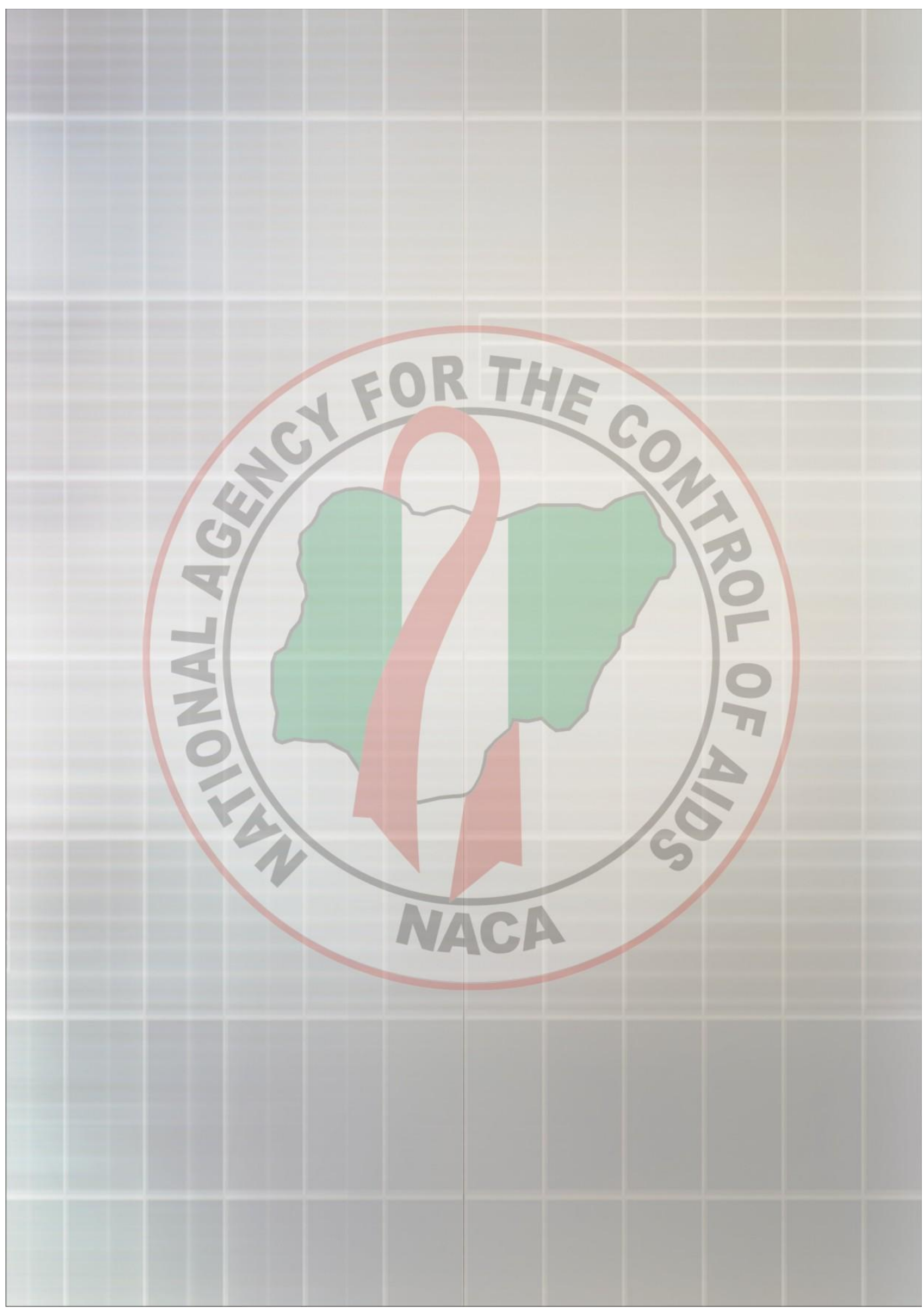

